bioRxiv preprint doi: https://doi.org/10.1101/2020.11.15.383620; this version posted November 15,2020 . The copyright holder for this preprint

(which was not certified by peer review) is the author/funder, who has granted bioRxiv a license to display the preprint in perpetuity. It is made available under aCC-BY-NC-ND 4.0 International license.

\title{
Role of $\beta$-arrestin- 2 in short- and long-term opioid tolerance in the dorsal root ganglia
}

Karan H. Muchhala ${ }^{a}$, Joanna C. Jacob ${ }^{a}$, William L. Dewey ${ }^{a}$, Hamid I. Akbarali. ${ }^{a}{ }^{*}$

a. Department of Pharmacology and Toxicology, Virginia Commonwealth University, 1112 East Clay St,

Richmond, VA 23298, USA

Corresponding author: Hamid I. Akbarali, PhD

Department of Pharmacology and Toxicology, Virginia Commonwealth University

1112 East Clay Street, Richmond, VA 23298, USA

Phone: 804-828-9688

Email: hamid.akbarali@vcuhealth.org

Declarations of interest: none 
bioRxiv preprint doi: https://doi.org/10.1101/2020.11.15.383620; this version posted November 15,2020 . The copyright holder for this preprint

(which was not certified by peer review) is the author/funder, who has granted bioRxiv a license to display the preprint in perpetuity. It is made available under aCC-BY-NC-ND 4.0 International license.

\section{CRediT author contributions}

Karan H. Muchhala: Investigation, Data Curation, Formal analysis, Methodology, Writing - Original Draft and Visualization.

Joanna C. Jacob: Investigation, Data Curation, Formal analysis, Methodology and Writing - Review \& Editing.

William L. Dewey: Supervision and Writing - Review \& Editing.

Hamid I. Akbarali: Conceptualization, Writing - Review \& Editing, Resources, Project administration and Funding acquisition. 


\begin{abstract}
$\beta$-arrestin-2 has been implicated in the mechanism of opioid-induced antinociceptive tolerance. Gprotein-biased agonists with reduced $\beta$-arrestin- 2 activation are being investigated as safer alternatives to clinically-used opioids. Opioid-induced analgesic tolerance is classically considered as centrallymediated, but recent reports implicate nociceptive dorsal root ganglia (DRG) neurons as critical mediators in this process. Here, we investigated the role of $\beta$-arrestin- 2 in the mechanism of opioid tolerance in DRG nociceptive neurons using $\beta$-arrestin-2 knockout mice and the G-protein-biased $\mu$ opioid receptor agonist, TRV130. Whole-cell current-clamp electrophysiology experiments revealed that 15-18-hour overnight exposure to $10 \mu \mathrm{M}$ morphine in vitro induced acute tolerance in $\beta$-arrestin-2 wildtype but not knockout DRG neurons. Furthermore, in wild-type DRG neurons circumventing $\beta$-arrestin-2 activation by overnight treatment with 200 nM TRV130 attenuated tolerance. Similarly, in $\beta$-arrestin-2 knockout male mice acute antinociceptive tolerance induced by $100 \mathrm{mg} / \mathrm{kg}$ morphine s.c. was prevented in the warm-water tail-withdrawal assay. Treatment with $30 \mathrm{mg} / \mathrm{kg}$ TRV130 s.c. also inhibited antinociceptive tolerance in wild-type mice. Alternately, in $\beta$-arrestin-2 knockout DRG neurons tolerance induced by 7-day in vivo exposure to $50 \mathrm{mg}$ morphine pellet was conserved. Likewise, $\beta$ arrestin-2 deletion did not mitigate in vivo antinociceptive tolerance induced by 7-day exposure to 25 $\mathrm{mg}$ or $50 \mathrm{mg}$ morphine pellet in both female or male mice, respectively. Consequently, these results indicated that $\beta$-arrestin- 2 mediates acute but not chronic opioid tolerance in DRG neurons and to antinociception. This suggests that opioid-induced antinociceptive tolerance may develop even in the absence of $\beta$-arrestin-2 activation, and thus significantly affect the clinical utility of biased agonists.
\end{abstract}

Keywords: morphine, antinociception, biased agonism, TRV130, mu-opioid receptor, analgesic tolerance 


\section{Introduction}

$\mu$-opioid receptors (MORs) are known to engage scaffolding proteins called $\beta$-arrestins, which classically function to desensitize activated GPCRs through stearic inhibition, but can also activate molecular mechanisms independent of G-protein signaling (Lefkowitz, 1998; Lohse et al., 1990; Williams et al., 2013). Previously, studies have shown that genetic deletion or down-regulation of $\beta$-arrestin-2, or use of G-protein-biased agonists enhances antinociception and reduces antinociceptive tolerance in rodents, thus implicating $\beta$-arrestin- 2 in the mechanism of opioid-induced antinociceptive tolerance

8 (Bohn et al., 2000, 1999; DeWire et al., 2013; Grim et al., 2020; Manglik et al., 2016; Wang et al., 2016;

9 Yang et al., 2011).

Primary afferent neurons of the dorsal root ganglia (DRG), specifically the thinly myelinated $A \delta$ -

11 and unmyelinated C-fiber neurons, are first-order components of the ascending pain pathway. These

12 neurons generate and transduce chemical, mechanical and thermal noxious stimuli as action potentials

13 from the periphery to second-order neurons in the spinal cord, which synapse with neurons in the pain

14 center in the brain and with motor neurons of the spinal reflex arc (Stein and Machelska, 2011). Thus, nociceptive DRG neurons generate signals that eventually get processed in the CNS as "pain".

While the prevailing dogma is that opioid-induced analgesia and tolerance are centrally

17 mediated, recent studies have highlighted the critical role of nociceptive DRG neurons in the expression

18 of antinociception and induction of opioid tolerance. Selective deletion of MORs from Nav1.8-containing

19 DRG neurons diminished the ability of morphine to mitigate inflammatory pain (Weibel et al., 2013),

20 whereas elimination of MORs from the entire population of DRG neurons abolished the acute spinal and

21 supraspinal antinociceptive effects of opioids (Sun et al., 2020, 2019). Ablation of TRPV1-expressing DRG

22 neurons or conditional knockout of MORs on TRPV1-expressing DRG neurons reversed antinociceptive

23 tolerance (Chen et al., 2007; Corder et al., 2017), suggesting that MORs on primary afferent DRG

24 neurons could be important targets for the prevention of antinociceptive tolerance. Therefore, it is 
25 important to delineate the molecular mechanisms underlying cellular tolerance in DRG nociceptive 26 neurons, specifically the role of $\beta$-arrestin- 2.

27 In the present study, we investigated the role of $\beta$-arrestin- 2 in the mechanism of opioid 28 tolerance in small-diameter DRG nociceptive neurons using $\beta$-arrestin-2 knockout mice and the G29 protein-biased MOR agonist, TRV130 (DeWire et al., 2013). We demonstrate that acute or "short-term" 30 tolerance-manifested as a result of several hours (overnight) of opioid exposure (Williams et al., 31 2013)-in nociceptive DRG neurons is mediated by $\beta$-arrestin-2, whereas chronic or "long-term"

32 tolerance-developing due to seven days of opioid exposure (Williams et al., 2013) - is independent of

$33 \beta$-arrestin-2. Acute antinociceptive tolerance to in vivo exposure to TRV130 or morphine in mice for one

34 day is also attenuated in the absence of $\beta$-arrestin- 2 activation. However, chronic antinociceptive 35 tolerance to morphine in either male or female mice develops independent of the $\beta$-arrestin- 2 pathway.

36 In conclusion, the findings presented in this study indicate that $\beta$-arrestin- 2 is a critical mediator of acute 37 tolerance but does not underlie chronic tolerance in DRG nociceptive neurons. 


\section{Materials and Methods}

\subsection{Drugs and Chemicals}

Morphine sulfate pentahydrate and implantable morphine pellets $(25 \mathrm{mg}$ ) were obtained from the National Institutes of Health National Institute on Drug Abuse (Bethesda, MD). (+) TRV130 was obtained from Dr. Bruce Blough (Research Triangle Institute, NC). Pyrogen-free isotonic saline was purchased from Hospira (Lake Forest, IL). Dulbecco's modified Eagle's medium (DMEM)/F12, Neurobasal-A medium, $\mathrm{Ca}^{2+}$ and $\mathrm{Mg}^{2+}$-free Hank's balanced salt solution (HBSS), 50x B-27 supplement and L-glutamine were purchased from Gibco, Thermo Fisher Scientific (Waltham, MA). Penicillin/streptomycin/amphotericin B antibiotic-antimycotic solution and laminin were purchased from Corning (Corning, NY). Papain, glial cell line-derived neurotrophic factor (GDNF) and fetal bovine serum (FBS) were purchased from Worthington Biochemical Corporation (Lakewood, NJ), Neuromics (Edina, MN) and Quality Biological, (Gaithersburg, MD), respectively. Glass cover slips were purchased from ThermoFisher Scientific (Waltham, MA). Twenty-four-well culture dishes and $35 \times 10 \mathrm{~mm}$ petri dishes were purchased from CELLTREAT (Pepperell, MA). Collagenase from Clostridium histolyticum, poly-D-lysine, $\mathrm{CaCl}_{2}, \mathrm{MgCl}_{2}, \mathrm{NaCl}, \mathrm{KCl}$, HEPES, EGTA, $\mathrm{NaH}_{2} \mathrm{PO}_{4}$, glucose, $\mathrm{Na}_{2} \mathrm{ATP}, \mathrm{NaGTP}$, L-aspartic acid (K salt), $\mathrm{KOH}, \mathrm{NaOH}, \mathrm{MgSO}_{4}$ and $\mathrm{NaHCO}_{3}$ were purchased from MilliporeSigma (Burlington, $\mathrm{MA}$ ).

\subsection{Animals}

All animal care and experimental procedures were conducted in accordance with procedures reviewed and approved by the Institutional Animal Care and Use Committee at Virginia Commonwealth University in compliance with the US National Research Council's Guide for the Care and Use of Laboratory Animals, the US Public Health Service's Policy on Humane Care and Use of Laboratory Animals, and Guide for the Care and Use of Laboratory Animals. 
Male and female $\beta$-arrestin-2 ( $\beta$ arr2) knockout (KO) or their wild-type (WT) littermates were

62 separately group-housed by genotype with up to five animals per IVC cage in animal-care quarters

63 maintained at $22^{\circ} \mathrm{C} \pm 2{ }^{\circ} \mathrm{C}$ on a 12 -hour light/dark cycle. Mice used in experimental procedures were at

64 least 7 weeks of age. Male $\beta$-arrestin-2 mice weighed $20-25 \mathrm{~g}$, and female $\beta$-arrestin-2 mice weighed 19-

$6523 \mathrm{~g}$. Mice were acclimated in the vivarium for at least one week prior to experimentation. Breeding

66 pairs for the $\beta$-arrestin-2 mice were initially obtained from Dr. Lefkowitz (Duke University, Durham, NC)

67 and housed within the transgenic facility at Virginia Commonwealth University. The genetic background

68 of the $\beta$-arrestin-2 WT and KO mice used in our experimental procedures was 81\% C57B6J:19\% C57B6N.

69 Mice had access to food and water ad libitum unless specified otherwise.

\section{2.3. In vivo morphine treatment}

Subcutaneously implanted continuous-release morphine pellets were used to model chronic in

73 vivo exposure as pellets maintain a high plasma level of morphine over a longer period of time

74 compared to intermittent injections or osmotic pumps and the tolerance induced is more robust (Dighe

75 et al., 2009; McLane et al., 2017). Where indicated, one or two 25 mg morphine pellets were implanted

76 subcutaneously in the dorsum of female or male $\beta$-arrestin- 2 mice for 7 days, respectively. This dose

77 was based on a previous study, where we demonstrated that a 7-day exposure to one $25 \mathrm{mg}$ and two 25

$78 \mathrm{mg}$ morphine pellets in female and male $\beta$-arrestin-2 mice, respectively, substantially right-shifted the

79 morphine dose response curve compared to wild-type mice in the warm-water tail-withdrawal assay,

80 indicating antinociceptive tolerance (Muchhala et al., 2020). The dose of two $25 \mathrm{mg}$ morphine pellets is

81 henceforth denoted as "50 mg" in the present study. In all experiments, control mice were implanted

82 with one or two placebo pellets. In order to implant the pellet, mice were first anesthetized with $2.5 \%$

83 isoflurane before shaving the hair from the base of the neck. Skin was disinfected with $10 \%$ povidone

84 iodine (General Medical Corp, Walnut, CA) and alcohol. A $1 \mathrm{~cm}$ horizontal incision was made at the base 
85 of the neck and one or two pellets were inserted in the subcutaneous space. The surgical site was closed

86 with Clay Adams Brand, MikRon AutoClip 9-mm wound clips (Becton Dickinson, Franklin Lakes, NJ) and

87 cleansed with $10 \%$ povidone iodine. Use of aseptic surgical techniques minimized any potential

88 contamination of the pellet, incision and subcutaneous space. Mice were allowed to recover in their

89 home cages where they remained throughout the experiment.

A repeated injection schedule as described previously by Bohn et al. (Bohn et al., 2002) was also

91 used to induce acute antinociceptive tolerance. Here, mice were injected subcutaneously with a high

92 dose of morphine (100 mg/kg s.c.) or TRV130 (30 mg/kg s.c.) on Day 1. Control mice received saline. On

93 the next day, antinociceptive tolerance was assessed using the warm-water tail-withdrawal assay (as

94 described below) by injecting mice with either $10 \mathrm{mg} / \mathrm{kg}$ morphine s.c. or $3 \mathrm{mg} / \mathrm{kg}$ TRV130 s.c. The doses

95 of TRV130 used in this experiment were adjusted to their morphine equivalents.

\section{2.4. Evaluating thermal nociception}

Thermal nociception was examined using the warm-water tail-withdrawal test, which represents

99 the sensory aspects of spinally-mediated acute pain and has been classically used to test the efficacy of

100 opioid analgesics (Mogil, 2009). In the warm-water tail-withdrawal assay, mice were gently secured in a

101 cloth and the distal $1 / 3^{\text {rd }}$ of the tail was immersed in a water bath warmed to $56^{\circ} \mathrm{C} \pm 0.1^{\circ} \mathrm{C}$. The latency

102 to withdraw the tail from the water was recorded. A maximum cut-off of 10 seconds was set to prevent

103 damage to the tail. Only naïve mice with control latency between 2 and 4 seconds were used in

104 experiments. Tolerance was assessed by challenging mice with an acute subcutaneous injection of

105 morphine or TRV130. Challenge latency was compared against baseline latency. Where indicated,

106 antinociception was quantified as \%MPE, which was calculated as follows: \%MPE= [(Challenge latency-

107 baseline latency)/ (10-baseline latency)] x 100, adapted from Harris and Pierson, 1964 (Harris and

108 Pierson, 1964). 


\subsection{Behavioral testing}

All testing was conducted in a temperature and light-controlled room in the light phase of the

112 12-hour light/dark cycle. Mice were acclimated to the testing room for at least 15-18 hours before

113 commencing experiments to mitigate stress to the animals and eliminate confound from potential

114 stress-induced effects on antinociception (Sorge et al., 2014). All animals were randomly divided into

115 control and treatment groups. Mice were excluded from experiments if they exhibited wounds from

116 aggressive interactions with cage mates, since injury-induced activation of the endogenous opioid

117 system could confound nociceptive assays (Corder et al., 2013).

\subsection{Isolation and primary culture of dorsal root ganglia neurons}

Dorsal root ganglia (DRG) cells were prepared from adult mice as previously described (Ross et

al., 2012). Mice were sacrificed via $\mathrm{CO}_{2}$ inhalation and L5 - S1 DRGs were immediately harvested using a

122 dissecting microscope. DRGs were placed in a $35 \mathrm{~mm}$ dish containing Hank's balanced salt solution

123 (HBSS) and papain $(15 \mathrm{U} / \mathrm{ml})$ was added prior to incubation at $37^{\circ} \mathrm{C}$ for 18 minutes. After the initial

124 incubation step, ganglia were transferred to a new $35 \mathrm{~mm}$ dish containing HBSS and $1.5 \mathrm{mg} / \mathrm{ml}$

125 collagenase from Clostridium histolyticum and incubated for 1 hour at $37^{\circ} \mathrm{C}$. DRGs were then

126 transferred to a sterile $15 \mathrm{ml}$ conical tube containing ice-cold $\left(4^{\circ} \mathrm{C}\right) \mathrm{DMEM} / \mathrm{F} 12$ supplemented with $10 \%$

127 FBS and dissociated by trituration before being centrifuged at $350 \times \mathrm{g}$ for 5 minutes. The supernatant

128 was decanted and the pellet was resuspended in neurobasal A media that contained $1 \% \mathrm{FBS}, 1 \times \mathrm{B}-27$

129 supplement, $10 \mathrm{ng} / \mathrm{ml}$ GDNF, $2 \mathrm{mM} \mathrm{L-glutamine,} \mathrm{and} 100 \mathrm{U} / \mathrm{ml}$ penicillin/streptomycin/amphotericin B

130 (complete neuron media). Cells were then plated on glass cover slips (1/well) coated with laminin and

131 poly-D-lysine. Twenty-four-well plates containing isolated DRGs were then incubated overnight at $37^{\circ} \mathrm{C}$

132 in a humidified $5 \% \mathrm{CO}_{2}$ /air stabilized incubator. Whole-cell patch clamp electrophysiology experiments 
133 were conducted 15-18 hours later on the following day. Where indicated, neurons were exposed to 10

$134 \mu \mathrm{M}$ morphine sulfate pentahydrate or $200 \mathrm{nM}$ TRV130 in complete neuron media for 15-18 hours

135 (overnight) prior to whole-cell patch clamp experiments to mimic prolonged opioid exposure.

136 Cells were also isolated from male $\beta$-arrestin-2 WT or KO mice subcutaneously implanted with $50 \mathrm{mg}$

137 morphine pellet for 7 using the procedure described above. Isolated cells were incubated as described

138 above in Neurobasal-A media supplemented with growth factors and antibiotic-antimycotic solution for

$139 \quad 15-18$ hours.

\subsection{Whole-cell patch clamp electrophysiology}

142 Micropipettes for patch clamp experiments (2-4 M $\Omega$ ) were made from pulled (Model P-97

143 Flaming-Brown Micropipette Puller, Sutter Instruments, Novato, CA) and fire-polished 1.5/0.84 o.d./i.d.

$144(\mathrm{~mm})$ borosilicate glass capillaries (World Precision Instruments, Sarasota, FL). The internal physiological

145 solution was composed of $100 \mathrm{mM}$ L-aspartic acid (K salt), $30 \mathrm{mM} \mathrm{KCl}, 4.5 \mathrm{mM} \mathrm{Na} 2 \mathrm{ATP}, 1 \mathrm{mM} \mathrm{MgCl}, 10$

$146 \mathrm{mM}$ HEPES, $0.1 \mathrm{mM}$ EGTA and $0.5 \mathrm{mM} \mathrm{NaGTP}$ and $\mathrm{pH}$ adjusted to 7.2 with $3 \mathrm{M} \mathrm{KOH}$. Coverslips with

147 adherent cells were transferred to a microscope stage plate continuously superfused with external

148 physiological salt solution composed of $135 \mathrm{mM} \mathrm{NaCl}, 5.4 \mathrm{mM} \mathrm{KCl}, 0.33 \mathrm{mM} \mathrm{NaH}{ }_{2} \mathrm{PO}_{4}, 5 \mathrm{mM}$ HEPES, 5

$149 \mathrm{mM}$ glucose, $2 \mathrm{mM} \mathrm{CaCl} 2$ and $1 \mathrm{mM} \mathrm{MgCl}_{2}$, and adjusted to a $\mathrm{pH}$ of 7.4 with $1 \mathrm{M} \mathrm{NaOH}$. Whole-cell

150 current-clamp recordings were made in a room temperature environment using HEKA EPC 10 (HEKA,

151 Bellmore, NY) or Axopatch 200B (Molecular Devices, Sunnyvale, CA) amplifiers at a $10 \mathrm{kHz}$ sampling

152 frequency and $2.9 \mathrm{kHz}$ low-pass Bessel filtering. Pulse generation and data acquisition were achieved

153 with PatchMaster v2x60 (HEKA) or Clampex and Clampfit 10.2 software (Molecular Devices). The

154 current-clamp protocol consisted of $10 \mathrm{pA}$ steps, beginning at $-30 \mathrm{pA}$ to assess both active and passive

155 cell properties. All current clamp recordings were performed two-five minutes after achieving whole-cell

156 mode to allow dialysis of internal solution. Pre- "baseline" recordings were taken to ensure cell stability 
157 before beginning drug perfusion. Once neurons were deemed stable, the external solution source was

158 exchanged for the external solution containing $3 \mu \mathrm{M}$ morphine or $50 \mathrm{nM}$ TRV130. A recording was taken

159 immediately following this exchange, and was labeled " $\mathrm{T}_{0}$ " or time zero, which served as the "baseline"

160 recording in all studies. A recording was then taken for up to 16 minutes to capture neuronal responses

161 to morphine or TRV130. Electrical properties such as threshold potential $\left(\mathrm{V}_{\text {thresh }}\right)$, rheobase, resting

162 membrane potential $\left(V_{\text {rest }}\right)$ and input resistance $\left(R_{\text {input }}\right)$ were extrapolated from each recording, and the

163 difference between baseline and following drug exposure was calculated for each cell. Action potential

164 (AP) derivatives were determined using the differential function in the PatchMaster or Clampfit

165 software, where the derivative of the voltage with respect to time $(\mathrm{dV} / \mathrm{dt})$ was calculated in order to

166 estimate threshold potential. Threshold potential was defined as the voltage at which dV/dt significantly

167 deviated from zero during the course of the action potential uprise. It was used as the primary measure

168 of neuronal excitability in our experiments. Each coverslip was discarded following drug exposure and

169 the same process was repeated on a freshly-mounted coverslip. Cellular tolerance was assessed

170 identically in cells either incubated with 200 nM TRV130 or $10 \mu \mathrm{M}$ morphine overnight, or isolated from

171 male mice implanted with two $25 \mathrm{mg}$ morphine pellets for 7 days. Values reported were not corrected

172 for junction potentials $(\sim 12 \mathrm{mV})$.

173 Experiments were performed only on cells with healthy morphology and stable patch. In DRG

174 primary isolations, small-diameter neurons ( $<30 \mathrm{pF}$ capacitance) correspond to nociceptive $A \delta$ fiber and

175 C-type neurons (Abraira and Ginty, 2013; Barabas et al., 2014), therefore we preferentially selected

176 these cells for use in our experiments. Due to the presence of multiple subtypes of small-diameter DRG

177 neurons in our primary cultures, measures from individual neurons were considered as independent

178 values and not replicates for data analysis. In all electrophysiology experiments ' $n$ ' represents the

179 number of neurons per group and ' $N$ ' denotes number of animals per group. 


\section{$181 \quad$ 2.8. Data and statistical analysis}

182 Data analysis was performed in GraphPad Prism 8.0 (GraphPad Software, Inc., La Jolla, CA). Data

183 are expressed as mean \pm S.E.M. Depending on the experimental design data were analyzed using 2-

184 tailed unpaired Student's t-test, 2-way ANOVA or 2-way repeated measures ANOVA. Select data were

185 also analyzed by multiple 2-tailed paired t-tests with two-stage step-up method of Benjamini, Krieger

186 and Yekutieli, and a false discovery rate of $5 \%$. Where specified in electrophysiology experiments, 3-way

187 repeated-measures ANOVA was used to evaluate the main effect of three independent variables on

188 action potential threshold, rheobase, resting membrane potential or input resistance. Bonferroni's

189 multiple comparisons post-hoc test was conducted only if the F value in the ANOVA table was significant

190 (Curtis et al., 2018). An alpha level of 0.05 was pre-determined. Thus, data were statistically significant

191 when $\mathrm{P}<0.05$. The specific statistical tests used for data analysis are indicated in the text or figure

192 legends. Sample sizes were based on our previous studies with similar experimental protocols. 


\section{Results}

\section{1. $\beta$-arrestin-2 knockout prevents the development of short-term tolerance in DRG neurons} exposure is mediated by $\beta$-arrestin-2. For this purpose, we harvested DRG neurons from male $\beta$ arrestin-2 WT or KO mice and incubated them in media containing $10 \mu \mathrm{M}$ morphine for $15-18$ hours (overnight). Cellular tolerance was assessed in only small-diameter DRG neurons (membrane capacitance $<30 \mathrm{pF}$ ) by challenging them with $3 \mu \mathrm{M}$ morphine (Fig. 1). We used threshold potential, which is the membrane potential at which action potential is elicited, as the primary metric of neuronal excitability. An increase in threshold potential from baseline represented reduced neuronal excitability, whereas a cell was described as "tolerant" if the acute challenge had no effect on threshold potential. In untreated DRG neurons from both $\beta$-arrestin-2 WT and KO mice, acute $3 \mu \mathrm{M}$ morphine significantly increased action potential threshold from baseline (WT: $-16.5 \pm 2.1 \mathrm{mV}$ to $-11.4 \pm 2.0 \mathrm{mV}, \mathrm{P}<0.001$; KO: $\mu \mathrm{M}$ morphine overnight were challenged with $3 \mu \mathrm{M}$ morphine $(-18.2 \pm 1.5 \mathrm{mV}$ to $-17.9 \pm 1.8 \mathrm{mV}, \mathrm{P}>0.05$; significantly decreased compared to the shift of $5.0 \pm 1.1 \mathrm{mV}$ in naïve $\beta$ arr2 $\mathrm{WT}$ neurons $(\mathrm{P}<0.01$; Fig.

210 1D). These data together signify the development of cellular tolerance in overnight morphine-treated

211 WT neurons. However, unlike WT neurons, ßarr2 KO DRG neurons exhibited reduced threshold

212 potentials in response to the acute $3 \mu \mathrm{M}$ morphine challenge despite being exposed to $10 \mu \mathrm{M}$ morphine 213 overnight $(-19.9 \pm 3.0 \mathrm{mV}$ to $-15.5 \pm 3.9 \mathrm{mV}, \mathrm{P}<0.001$; Figs. $1 \mathrm{~B}$ and $1 \mathrm{C}$; Table S1). The shift in threshold 214 potential of $4.4 \pm 1.1 \mathrm{mV}$ in overnight morphine-treated $\beta$ arr2 $\mathrm{KO}$ neurons was not significantly different

215 from the threshold potential change of $4.3 \pm 0.8 \mathrm{mV}$ in naïve $\beta$ arr2 $\mathrm{KO}$ neurons ( $\mathrm{P}>0.05$; Fig. 1D) 216 indicating that individual neurons devoid of $\beta$-arrestin-2 did not become tolerant to morphine. Analysis 


\subsection{TRV130 does not produce short-term tolerance in DRG neurons}

We next studied the effects of TRV130, a G-protein biased agonist that does not promote the

233 incubation in $200 \mathrm{nM}$ TRV130, neurons challenged with $50 \mathrm{nM}$ TRV130 on Day 2 continued to show

234 statistically significant positive shifts in threshold potential compared to baseline $(-12.8 \pm 0.9 \mathrm{mV}$ to -

$23510.0 \pm 1.0 \mathrm{mV}, \mathrm{P}<0.05$, Figs. 2B and 2C, Table S2), indicating that overnight TRV130 exposure did not

236 produce tolerance in individual DRG neurons. Analysis of the entire TRV130 dataset in Figure 2C by 2-

237 way repeated-measures ANOVA did not reveal a significant main effect of overnight TRV130 treatment

238 versus acute TRV130 challenge on action potential threshold $[F(1,16)=0.27 ; P=0.61 ;$ Table S2].

239 Furthermore, in both naïve and overnight TRV130-treated neurons the mean threshold potential change 
following acute TRV130 challenge is not significantly different (Naïve: $3.6 \pm 1.0$ vs. Overnight-treated: 2.8

$241 \pm 1.2$; Fig. 2D).

These studies show that $\beta$-arrestin-2-induced desensitization of the MOR mediates short-term opioid tolerance in DRG nociceptors.

\subsection{Acute antinociceptive tolerance in-vivo is dependent on $\beta$-arrestin-2.}

In order to test if the development of acute antinociceptive tolerance in-vivo is dependent on $\beta$ -

247 arrestin-2, we utilized a short-term tolerance injection schedule previously published by Bohn et al.

248 (Bohn et al., 2002) and tested antinociception using the warm-water tail withdrawal assay. Morphine

249 was assessed in both $\beta$-arrestin-2 WT and KO male mice, while the effects of TRV130 were only assessed

250 in male WT mice as TRV130 prevents $\beta$-arrestin-2 activation. Mice were considered drug-responsive if

251 the acute challenge dose significantly increased tail-withdrawal latency. Alternately, mice were deemed

252 tolerant if the acute challenge dose did not significantly increase tail-withdrawal latency. Mice that

253 received saline on Day 1 exhibited antinociception to their respective challenge dose of $10 \mathrm{mg} / \mathrm{kg}$

254 morphine s.c. or $3 \mathrm{mg} / \mathrm{kg}$ TRV130 s.c. on Day 2 (Fig. 3). As predicted, WT mice that received a high dose

255 of morphine (100 mg/kg, s.c.) on Day 1 showed tolerance development when challenged on Day 2 (38.5

$256 \pm 12.6 \% \mathrm{MPE}$ ), as compared to saline pre-treated WT controls acutely challenged with $10 \mathrm{mg} / \mathrm{kg}$

257 morphine on Day 2 (85.2 $\pm 10.1 \% \mathrm{MPE}, \mathrm{P}=0.007$; Fig. 3A). In $\beta$-arrestin-2 KO mice however, high dose

258 morphine exposure on Day 1 did not lead to tolerance development when they were challenged on Day

2592 (91.2 \pm 8.8 \%MPE vs. saline controls: $89 \pm 11.0$, P>0.05; Fig. 3A). Furthermore, 3 mg/kg TRV130 was

260 equally effective as morphine in producing an acute antinociceptive effect (100.0 $\pm 0.0 \% \mathrm{MPE}$; Fig 3B). A

261 high dose of TRV130 (30 mg/kg, s.c.) given on Day 1 did not lead to tolerance development following a

262 challenge injection on Day $2(84.72 \pm 15.3 \% \mathrm{MPE})$ as compared to acute TRV130 wild type controls

263 (100.0 $\pm 0.0 \% \mathrm{MPE}, \mathrm{P}>0.05 ;$ Fig. 3B). 
Altogether, these results support the previously published finding that $\beta$-arrestin- 2 mediates

265 acute antinociceptive tolerance at the whole animal level.

\subsection{Long-term exposure to morphine induces tolerance in DRG neurons independent of $\beta$-arrestin-2}

We investigated whether tolerance after long-term exposure to morphine is mediated by $\beta$ -

arrestin-2. In order to test this, DRG neurons were collected from male $\beta$-arrestin-2 WT or KO mice subcutaneously implanted with a $50 \mathrm{mg}$ morphine pellet for 7 days. As in previous studies, cellular tolerance was assessed by challenging small-diameter DRG neurons (membrane capacitance $<30 \mathrm{pF}$ )

272 with $3 \mu \mathrm{M}$ morphine in the bath and action potential threshold was used as the indicator of cellular

273 excitability (Fig.4). The $3 \mu \mathrm{M}$ morphine challenge did not appear to produce a shift in action potential

274 threshold from baseline values of DRG neurons obtained from ßarr2 WT mice exposed to $50 \mathrm{mg}$

275 morphine pellet for 7 days $(-22.3 \pm 2.3 \mathrm{mV}$ to $-22.2 \pm 2.2 \mathrm{mV}$; Figs. 4A and 4C; Table S3). Interestingly, 3

$276 \mu \mathrm{M}$ morphine also appeared to not alter the threshold potential from baseline of DRG neurons isolated

277 from 7-day $50 \mathrm{mg}$ morphine-pelleted $\beta$ arr2 $\mathrm{KO}$ animals $(-17.9 \pm 1.8 \mathrm{mV}$ to $-19.1 \pm 1.7 \mathrm{mV}$; Figs. $4 \mathrm{~B}$ and

278 4C; Table S3). Analysis of the entire dataset by 2-way repeated-measures ANOVA did not detect an

279 effect of acute morphine challenge on threshold potential $[F(1,15)=1.20 ; P=0.29]$. The ANOVA analysis

280 also did not reveal a significant main effect of genotype versus acute morphine challenge on action

281 potential threshold $[\mathrm{F}(1,15)=1.565 ; \mathrm{P}=0.23]$. Furthermore, mean threshold potential change after

282 acute morphine challenge was not significantly different between the WT and KO DRG neurons $(P>0.05$

283 by 2-tailed unpaired t-test; Fig. 4D). No significant effect of genotype and acute morphine challenge on

284 rheobase, resting membrane potential or input resistance was observed (Table S3). Altogether, these

285 data indicated the development of morphine tolerance in DRG neurons from morphine-pelleted $\beta$ arr2

286 WT and KO male mice. 

required for long-term tolerance to morphine in DRG neurons.

\subsection{Long-term morphine tolerance to antinociception is not altered by $\beta$-arrestin-2 deletion in either}

We investigated whether $\beta$-arrestin-2 modulates the development of chronic or "long-term" antinociceptive tolerance in mice. To induce tolerance, male and female mice were implanted

294 subcutaneously with $50 \mathrm{mg}$ or $25 \mathrm{mg}$ morphine pellets, respectively, in accordance with a previous report by our laboratory (Muchhala et al., 2020). We determined the development of tolerance over 7 days by an acute challenge of morphine (10 mg/kg morphine s.c). Response to the challenge dose was tested on Days 1, 3, 4 and 7 post pellet implantation. Pre-injection baseline latency was compared with post-injection latency on these days. Mice sensitive to morphine-induced antinociception exhibited increased tail-withdrawal latencies that were at or close to the 10-second maximum cutoff. Mice were regarded as tolerant if the acute morphine challenge failed to induce antinociception i.e. no statistically significant change $(P>0.05)$ in tail-withdrawal latency from baseline. As predicted, $10 \mathrm{mg} / \mathrm{kg}$ morphine increased tail-withdrawal latency of most placebo-pelleted mice (46/49 mice) to the maximum cutoff of

30310 seconds (Fig. 5 for males and Fig. 6 for females). In 1-day morphine-pelleted male $\beta$ arr2 WT and KO 304 mice, the baseline tail-withdrawal latency was at the 10-second maximum cutoff, indicating morphine305 induced antinociception (Fig. 5A). The baseline reduced in 3 out of 7 mice in the WT cohort by day 3 306 indicative of a slow development of tolerance. All ßarr2 KO male mice continued to exhibit maximal 307 baseline tail-withdrawal latencies three days after morphine pellet exposure (Fig. 5B). Interestingly, after

308 four days of morphine pellet exposure the antinociceptive effect of the morphine challenge 309 extinguished in both male $\beta$ arr2 WT and KO animals ( $P>0.05$ vs. baseline by 2-way repeated-measures 310 ANOVA with Bonferroni's post-test), indicating the development of morphine tolerance despite $\beta$ - 
311 arrestin-2 deletion (Fig. 5C). Tolerance to $10 \mathrm{mg} / \mathrm{kg}$ morphine was observed in all male mice (7/7 WT

312 mice and 8/8 KO mice; $\mathrm{P}>0.05$ vs. baseline by 2-way repeated-measures ANOVA with Bonferroni's post-

313 test) after 7 days of morphine exposure (Fig. 5D). Thus, $\beta$-arrestin-2 knockout neither shifted the time-

314 course of morphine tolerance nor prevented the manifestation of morphine tolerance in male mice.

315 Similar to observations in male mice, 1-day morphine-pelleted female mice exhibited the

316 maximum 10-second cutoff baseline latency (Fig. 6A). After three days of morphine exposure, 10/11

317 Barr2 WT and 3/6 KO mice responded in the tail-withdrawal test at baseline, i.e. submaximal baseline

318 tail-withdrawal latencies were observed (Fig. 6B). Acute $10 \mathrm{mg} / \mathrm{kg}$ morphine challenge, however, did not

319 significantly increase antinociception compared to baseline in either genotype (Fig. 6B; P>0.05 vs.

320 baseline by 2-way repeated-measures ANOVA). The lack of response to the morphine challenge was also

321 evident in 4-day and 7-day morphine-pelleted female WT mice, indicating the development of morphine

322 tolerance (Figs. 6C and 6D). In contrast, $10 \mathrm{mg} / \mathrm{kg}$ morphine produced antinociception in female $\beta$ arr2

323 KO mice exposed to morphine for four days (Fig. 6C; $\mathrm{P}<0.001$ vs. baseline by 2-way repeated-measures

324 ANOVA with Bonferroni's post-test). This trend was also observed in 3/6 7-day morphine-pelleted

325 female $\beta$ arr2 KO mice. The remaining mice exhibited tolerance to the morphine challenge (Fig. 6D; P

$326=0.06$ vs. baseline by 2 -way repeated-measures ANOVA). Altogether, these data suggest that $\beta$-arrestin-

3272 might not mediate the development of morphine tolerance in female mice.

328 Finally, we evaluated whether there were sex differences in antinociceptive tolerance in $\beta$ arr2

329 KO mice. A cumulative dose-response to morphine was conducted in male and female mice (Fig. 7).

330 Morphine-induced antinociception was quantitated as \% MPE, where 100\% MPE represented maximal

331 antinociception. $\mathrm{ED}_{50}$ values of 7-day placebo-pelleted male and female KO mice were 2.90 (1.89-4.33)

$332 \mathrm{mg} / \mathrm{kg}$ and $1.56(1.25-1.98) \mathrm{mg} / \mathrm{kg}$, respectively. Morphine pre-treatment for 7 days produced a

333 significant rightward shift in the dose response curve of both male and female mice, irrespective of

334 genotype (Fig. 7). The $\mathrm{ED}_{50}$ values for 7-day morphine-pelleted male and female mice were 63.9 (42.4- 
336 tolerance was induced in Barr2 KO mice, irrespective of the sex.

338 tolerance in either male or female mice.

\section{4. Discussion}

The CNS is traditionally considered as the primary site of opioid-induced antinociceptive

341 tolerance and, therefore, research has primarily focused on delineating mechanisms underlying opioid

342 tolerance in centrally-localized MORs. However, systemically-administered opioids can induce analgesia

343 by concomitantly activating MORs at multiple sites along the pain pathway, including the primary

344 afferent neurons of the DRG. MORs expressed on DRG primary afferent neurons are critical for

345 regulating the influx of nociceptive stimuli to the CNS. Activation of peripheral MORs can prevent the

346 sensitization of primary afferent neurons to noxious stimuli and attenuate subsequent CNS events

347 underlying the perception of pain. Alternately, desensitization of MORs on DRG neurons as a result of

348 chronic opioid exposure can render this process inactive. Recent studies have in fact demonstrated that

349 MORs expressed by nociceptive neurons of the DRG profoundly contribute to the induction of

350 antinociceptive tolerance in mice (Chen et al., 2007; Corder et al., 2017). It is therefore critical to

351 investigate mechanisms underlying opioid tolerance in DRG neurons.

In the present study, we observed that acute tolerance in single nociceptive DRG neurons and

353 to tail-withdrawal antinociception is prevented by genetic deletion of $\beta$-arrestin- 2 or by using TRV130, a

354 G-protein-biased agonist at the $\mu$-opioid receptor. In contrast, long-term morphine tolerance in

355 individual nociceptive DRG neurons and to tail-withdrawal antinociception in either male or female mice

356 develops independently of the $\beta$-arrestin-2 pathway. Taken together the findings presented here

357 indicate that the different phases of antinociceptive tolerance are regulated via distinct mechanisms-a

358 rapid $\beta$-arrestin-2-dependent mechanism that mediates acute tolerance, and a slow $\beta$-arrestin-2- 
independent mechanism that underlies long-term tolerance-in both mice and individual DRG neurons critical in the initiation of nociceptive stimuli. pain with reduced risks such as tolerance (Madariaga-Mazón et al., 2017; Siuda et al., 2017). In fact, the

364 G-protein biased MOR agonist, Olinvyk (TRV130), was recently approved by the FDA for short-term intravenous use in hospitals (U.S. Food and Drug Administration, 2020). The findings reported in the present study implicate that antinociceptive tolerance can develop in the absence of $\beta$-arrestin- 2 activation. Consequently, these findings raise questions about the usefulness of G-protein-biased agonists to mitigate opioid-induced analgesic tolerance.

371 membrane-delimited mechanisms is disrupted (Lohse et al., 1990). Multiple studies have implicated that

372 this $\beta$-arrestin-2 pathway is the basis of opioid-induced analgesic tolerance (Bohn et al., 2000; DeWire et

373 al., 2013; Grim et al., 2020; Manglik et al., 2016; Wang et al., 2016; Yang et al., 2011). Consistent with

374 these findings, in the present study we too observed that antinociceptive tolerance in mice and cellular

375 tolerance in nociceptive DRG neurons, specifically acute tolerance (Williams et al., 2013), is mediated by

$376 \beta$-arrestin-2. Interestingly, in the current study tolerance induced after long-term morphine exposure (7

377 days) in both mice and DRG neurons was not contingent on $\beta$-arrestin-2. Altogether, the data suggests

378 that $\beta$-arrestin-2 mediates only the acute but not the long-term phase of tolerance at the MOR. Indeed,

379 Bohn et al. have previously reported that the onset of antinociceptive tolerance in the warm-water tail-

380 withdrawal assay in mice is delayed but not prevented in the absence of $\beta$-arrestin-2 (Bohn et al., 2002).

381 In contrast, functional deletion of $\beta$-arrestin-2 in rats prevented the development of chronic morphine

382 tolerance to warm-water tail-withdrawal antinociception (Wang et al., 2016; Yang et al., 2011). This 
discrepancy could be due to species differences or disparate tolerance development models, for example daily injections vs. continuous-release subcutaneous pellets. It is well-known that the extent of tolerance produced by subcutaneous pellets is significantly greater than other techniques (Dighe et al., 2009) and therefore, tolerance produced by intermittent morphine injections might be more readily reversed compared to tolerance produced by morphine pellets. tolerance (Kang et al., 2017; Komla et al., 2019; Meng et al., 2013; Mischel et al., 2018). Antinociceptive tolerance in mice was attenuated by modulating the gut microbiome with antibiotics or probiotics (Kang morphine tolerance at the single-cell level in DRG neurons (Kang et al., 2017; Mischel et al., 2018).

394 Conversely, colonic inflammation enhanced the rate of morphine tolerance to antinociception (Komla et neurons might be mediated by changes induced within the gut microbiome.

400 variable influencing the role of $\beta$-arrestin-2 in the mechanism of antinociceptive tolerance. In the 401 present study, we find that antinociceptive tolerance in the warm-water tail-withdrawal assay develops

402 in both male and female mice even in the absence of $\beta$-arrestin-2, implicating that sex hormones might

403 not interact with the $\beta$-arrestin-2 pathway to mediate antinociceptive tolerance in mice. 
and $10 \mu \mathrm{M}$ morphine for overnight treatment). Previously, it has been reported in 8-week old male

$408 \mathrm{C} 57 \mathrm{BI} / 6 \mathrm{NCr}$ mice that a $25 \mathrm{mg}$ morphine pellet produces a peak plasma morphine concentration of

$4092695.3 \pm 785.1 \mathrm{ng} / \mathrm{mL}(\sim 3.5 \mu \mathrm{M}$ morphine) 24 hours after pellet implantation, which progressively

410 decreased to $229.5 \pm 92.5 \mathrm{ng} / \mathrm{mL}$ after 7 days ( $0.4 \mu \mathrm{M}$ morphine) (McLane et al., 2017). In humans,

411 therapeutic doses of morphine have been reported to produce serum concentrations of 14.7-70.4

$412 \mathrm{ng} / \mathrm{mL}$ (Netriova et al., 2006), whereas in overdose cases, wide-ranging plasma concentrations from of

$413113 \mathrm{ng} / \mathrm{mL}$ to $4660 \mathrm{ng} / \mathrm{mL}$ have been detected (Meissner et al., 2002; Ozaita et al., 2002). Thus, while

414 the amount of morphine delivered to mice and isolated neurons in our experiments is on the higher end

415 of what patients might receive in the clinic, it is comparable to what might be observed in opioid

416 abusers.

417 In conclusion, the findings presented in this study implicate that antinociceptive tolerance

418 involving peripheral MORs in the DRG is mediated by two disparate mechanisms- $\beta$-arrestin-2-

419 dependent and-independent pathways - that are engaged during different phases of opioid exposure.

420 This suggests that the contribution of $\beta$-arrestin-2-induced desensitization of MORs in the molecular

421 mechanism of tolerance is more intricate and that tolerance might be mediated by other means such as

422 microbial dysbiosis in the gut. Importantly, these findings help inform the clinical utility of chronic

423 exposure to G-protein-biased agonists over conventional opioids for pain management and highlights

424 considerations for the likelihood of developing analgesic tolerance.

\section{Acknowledgments}

427 The authors wish to thank David Stevens and Dr. Krista Scoggins for their technical assistance. This work

428 was supported by the National Institute of Health grants: P30 DA033934, R01 DA036975, R01

429 DA024009. 


\section{References}

431 Abraira, V.E., Ginty, D.D., 2013. The sensory neurons of touch. Neuron 79, 618-639.

$432 \quad$ https://doi.org/10.1016/j.neuron.2013.07.051

433 Barabas, M.E., Mattson, E.C., Aboualizadeh, E., Hirschmugl, C.J., Stucky, C.L., 2014. Chemical structure

434 and morphology of dorsal root Ganglion neurons from naive and inflamed mice. J. Biol. Chem. 289,

435 34241-34249. https://doi.org/10.1074/jbc.M114.570101

436 Bodnar, R.J., Kest, B., 2010. Sex differences in opioid analgesia, hyperalgesia, tolerance and withdrawal:

437 Central mechanisms of action and roles of gonadal hormones. Horm. Behav. 58, 72-81. https://doi.org/10.1016/j.yhbeh.2009.09.012

Bohn, L.M., Gainetdinov, R.R., Lin, F.T., Lefkowitz, R.J., Caron, M.G., 2000. $\mu$-opioid receptor desensitization by $\beta$-arrestin-2 determines morphine tolerance but not dependence. Nature 408 ,

Bohn, L.M., Lefkowitz, R.J., Caron, M.G., 2002. Differential mechanisms of morphine antinociceptive tolerance revealed in Barrestin-2 knock-out mice. J. Neurosci. 22, 10494-10500.

Bohn, L.M., Lefkowitz, R.J., Gainetdinov, R.R., Peppel, K., Caron, M.G., Lin, F.T., 1999. Enhanced morphine analgesia in mice lacking $\beta$-arrestin 2. Science (80-. ). 286, 2495-2498. https://doi.org/10.1126/science.286.5449.2495

448 Chen, S.-R., Prunean, A., Pan, H.-M., Welker, K.L., Pan, H.-L., 2007. Resistance to morphine analgesic tolerance in rats with deleted transient receptor potential vanilloid type 1-expressing sensory neurons. Neuroscience 145, 676-85. https://doi.org/10.1016/j.neuroscience.2006.12.016

451 Corder, G., Doolen, S., Donahue, R.R., Winter, M.K., Jutras, B.L., He, Y., Hu, X., Wieskopf, J.S., Mogil, J.S., 

leads to long-term endogenous analgesia and dependence. Science (80-. ). 341, 1394-1399. https://doi.org/10.1126/science.1239403

Corder, G., Tawfik, V.L., Wang, D., Sypek, E.I., Low, S.A., Dickinson, J.R., Sotoudeh, C., Clark, J.D., Barres, https://doi.org/10.1038/nm.4262

Craft, R.M., Stratmann, J.A., Bartok, R.E., Walpole, T.I., King, S.J., 1999. Sex differences in development of morphine tolerance and dependence in the rat. Psychopharmacology (Berl). 143, 1-7.

Curtis, M.J., Alexander, S., Cirino, G., Docherty, J.R., George, C.H., Giembycz, M.A., Hoyer, D., Insel, P.A., Izzo, A.A., Ji, Y., MacEwan, D.J., Sobey, C.G., Stanford, S.C., Teixeira, M.M., Wonnacott, S.,

467 DeWire, S.M., Yamashita, D.S., Rominger, D.H., Liu, G., Cowan, C.L., Graczyk, T.M., Chen, X.T., Pitis, P.M., Ahluwalia, A., 2018. Experimental design and analysis and their reporting II: updated and simplified guidance for authors and peer reviewers. Br. J. Pharmacol. 175, 987-993. opioid receptor is potently analgesic with reduced gastrointestinal and respiratory dysfunction

474 https://doi.org/10.1016/j.pbb.2009.02.004 
475 Grim, T.W., Schmid, C.L., Stahl, E.L., Pantouli, F., Ho, J.-H., Acevedo-Canabal, A., Kennedy, N.M.,

476 Cameron, M.D., Bannister, T.D., Bohn, L.M., 2020. A G protein signaling-biased agonist at the $\mu-$

477 opioid receptor reverses morphine tolerance while preventing morphine withdrawal.

478 Neuropsychopharmacology 45, 416-425. https://doi.org/10.1038/s41386-019-0491-8

479 Harris, L.S., Pierson, A.K., 1964. Some Narcotic Antagonists In The Benzomorphan Series. J. Pharmacol.

480 Exp. Ther. 143, 141-148. https://doi.org/1 Feb , 1964

481 Kalinichev, M., Easterling, K.W., Holtzman, S.G., 2001. Early neonatal experience of Long-Evans rats

482 results in long-lasting changes in morphine tolerance and dependence. Psychopharmacology (Berl).

483 157, 305-312. https://doi.org/10.1007/s002130100806

484 Kang, M., Mischel, R.A., Bhave, S., Komla, E., Cho, A., Huang, C., Dewey, W.L., Akbarali, H.I., 2017. The

485 effect of gut microbiome on tolerance to morphine mediated antinociception in mice. Sci. Rep. 7, 486 42658. https://doi.org/10.1038/srep42658

487 Kasson, B.G., George, R., 1984. Endocrine influences on the actions of morphine: IV. effects of sex and 488 strain. Life Sci. 34, 1627-1634. https://doi.org/10.1016/0024-3205(84)90633-7

489 Komla, E., Stevens, D.L., Zheng, Y., Zhang, Y., Dewey, W.L., Akbarali, H.I., 2019. Experimental Colitis

490 Enhances the Rate of Antinociceptive Tolerance to Morphine via Peripheral Opioid Receptors. J.

491 Pharmacol. Exp. Ther. 370, 504-513. https://doi.org/10.1124/jpet.119.256941

492 Lee, C.W.S., Ho, I.K., 2013. Sex differences in opioid analgesia and addiction: Interactions among opioid

493 receptors and estrogen receptors. Mol. Pain 9, 1-10. https://doi.org/10.1186/1744-8069-9-45

494 Lefkowitz, R.J., 1998. G protein-coupled receptors: III. New roles for receptor kinases and $\beta$ - arrestins in

495 receptor signaling and desensitization. J. Biol. Chem. https://doi.org/10.1074/jbc.273.30.18677

496 Lohse, M.J., Benovic, J.L., Codina, J., Caron, M.G., Lefkowitz, R.J., 1990. beta-Arrestin: a protein that

497 regulates beta-adrenergic receptor function. Science (80-. ). 248, 1547-1550. 
Madariaga-Mazón, A., Marmolejo-Valencia, A.F., Li, Y., Toll, L., Houghten, R.A., Martinez-Mayorga, K., 2017. Mu-Opioid receptor biased ligands: A safer and painless discovery of analgesics? Drug Discov. Today 22, 1719-1729. https://doi.org/10.1016/j.drudis.2017.07.002

Manglik, A., Lin, H., Aryal, D.K., McCorvy, J.D., Dengler, D., Corder, G., Levit, A., Kling, R.C., Bernat, V., Hübner, H., Huang, X.P., Sassano, M.F., Giguère, P.M., Löber, S., Duan, D., Scherrer, G., Kobilka, B.K., Gmeiner, P., Roth, B.L., Shoichet, B.K., 2016. Structure-based discovery of opioid analgesics

McLane, V.D., Bergquist, I., Cormier, J., Barlow, D.J., Houseknecht, K.L., Bilsky, E.J., Cao, L., 2017. Longwith reduced side effects. Nature 537, 185-190. https://doi.org/10.1038/nature19112

Meissner, C., Recker, S., Reiter, A., Friedrich, H.J., Oehmichen, M., 2002. Fatal versus non-fatal heroin term morphine delivery via slow release morphine pellets or osmotic pumps: Plasma concentration, analgesia, and naloxone-precipitated withdrawal. Life Sci. 185, 1-7.

Meng, J., Yu, H., Ma, J., Wang, J., Banerjee, S., Charboneau, R., Barke, R.A., Roy, S., 2013. Morphine Induces Bacterial Translocation in Mice by Compromising Intestinal Barrier Function in a TLR-

515 Mischel, R.A., Dewey, W.L., Akbarali, H.I., 2018. Tolerance to Morphine-Induced Inhibition of TTX-R 516 Sodium Channels in Dorsal Root Ganglia Neurons Is Modulated by Gut-Derived Mediators. iScience 2, 193-209. https://doi.org/10.1016/j.isci.2018.03.003 https://doi.org/10.1038/nrn2606 
on glutamate level in the nucleus accumbens in morphine tolerant rats: a microdialysis study. Eur.

523 Muchhala, K.H., Jacob, J.C., Alam, I., Hasan, S., Khan, A., Kang, M., Dewey, W.L., Akbarali, H.I., 2020.

524 Rapid tolerance to morphine in the myenteric neurons of the small intestine is independent of $\beta$ -

525 arrestin-2 and mediated by PKC. bioRxiv 2020.07.17.209437.

$526 \quad$ https://doi.org/10.1101/2020.07.17.209437

527 Netriova, J., Blahova, E., Johanesova, Z., Brandsteterova, E., Lehotay, J., Serdt, K., Mocak, J., 2006. HPLC 528 determination of morphine, morphine-3-glucuronide and morphine-6-glucuronide in human serum 529 of oncological patients after administration of morphine drugs. Pharmazie $61,528-34$.

530 Ozaita, A., Escribá, P. V., Ventayol, P., Murga, C., Mayor, F., García-Sevilla, J.A., 2002. Regulation of G 531 Protein-Coupled Receptor Kinase 2 in Brains of Opiate-Treated Rats and Human Opiate Addicts. J. Neurochem. 70, 1249-1257. https://doi.org/10.1046/j.1471-4159.1998.70031249.x

533 Pedersen, M.F., Wróbel, T.M., Märcher-Rørsted, E., Pedersen, D.S., Møller, T.C., Gabriele, F., Pedersen, 534 H., Matosiuk, D., Foster, S.R., Bouvier, M., Bräuner-Osborne, H., 2020. Biased agonism of clinically 535 approved $\mu$-opioid receptor agonists and TRV130 is not controlled by binding and signaling kinetics. Neuropharmacology 166, 107718. https://doi.org/10.1016/j.neuropharm.2019.107718

537 Ross, G.R., Gade, A.R., Dewey, W.L., Akbarali, H.I., 2012. Opioid-induced hypernociception is associated 538 with hyperexcitability and altered tetrodotoxin-resistant $\mathrm{Na}+$ channel function of dorsal root 539 ganglia. Am. J. Physiol. - Cell Physiol. 302, 1152-1161. https://doi.org/10.1152/ajpcell.00171.2011

540 Siuda, E.R., Carr, R., Rominger, D.H., Violin, J.D., 2017. Biased mu-opioid receptor ligands: a promising 541 new generation of pain therapeutics. Curr. Opin. Pharmacol. 32, 77-84.

$542 \quad$ https://doi.org/10.1016/j.coph.2016.11.007

543 Sorge, R.E., Martin, L.J., Isbester, K.A., Sotocinal, S.G., Rosen, S., Tuttle, A.H., Wieskopf, J.S., Acland, E.L., 
Dokova, A., Kadoura, B., Leger, P., Mapplebeck, J.C.S., McPhail, M., Delaney, A., Wigerblad, G.,

Stein, C., Machelska, H., 2011. Modulation of Peripheral Sensory Neurons by the Immune System:

549 Implications for Pain Therapy. Pharmacol. Rev. 63, 860-881.

551 Sun, J., Chen, S.R., Chen, H., Pan, H.L., 2019. $\mu$-Opioid receptors in primary sensory neurons are essential

552 for opioid analgesic effect on acute and inflammatory pain and opioid-induced hyperalgesia. J.

$553 \quad$ Physiol. 597, 1661-1675. https://doi.org/10.1113/JP277428

554 Sun, J., Chen, S.R., Pan, H.L., 2020. $\mu$-Opioid receptors in primary sensory neurons are involved in 555 supraspinal opioid analgesia. Brain Res. 1729, 146623.

556 https://doi.org/10.1016/j.brainres.2019.146623

557 U.S. Food and Drug Administration, 2020. FDA Approves New Opioid for Intravenous Use in Hospitals,

558 Other Controlled Clinical Settings. https://www.fda.gov/news-events/press-announcements/fda-

559 approves-new-opioid-intravenous-use-hospitals-other-controlled-clinical-settings (accessed 1

$560 \quad$ November 2020). https://doi.org/8-7-2020

561 Wang, J., Xu, W., Zhong, T., Song, Z., Zou, Y., Ding, Z., Guo, Q., Dong, X., Zou, W., 2016. MiR-365 targets

$562 \quad \beta$-arrestin 2 to reverse morphine tolerance in rats. Sci. Rep. 6, 1-11.

563 https://doi.org/10.1038/srep38285

564 Weibel, R., Reiss, D., Karchewski, L., Gardon, O., Matifas, A., Filliol, D., Becker, J.A.J., Wood, J.N., Kieffer,

565 B.L., Gaveriaux-Ruff, C., 2013. Mu Opioid Receptors on Primary Afferent Nav1.8 Neurons

566 Contribute to Opiate-Induced Analgesia: Insight from Conditional Knockout Mice. PLoS One 8, 
568 Williams, J.T., Ingram, S.L., Henderson, G., Chavkin, C., von Zastrow, M., Schulz, S., Koch, T., Evans, C.J.,

569 Christie, M.J., 2013. Regulation of $\mu$-opioid receptors: Desensitization, phosphorylation,

570 internalization, and tolerance. Pharmacol. Rev. 65, 223-254.

$571 \quad$ https://doi.org/10.1124/pr.112.005942

572 Yang, C.H., Huang, H.W., Chen, K.H., Chen, Y.S., Sheen-Chen, S.M., Lin, C.R., 2011. Antinociceptive

573 potentiation and attenuation of tolerance by intrathecal $\beta$-arrestin 2 small interfering RNA in rats.

574 Br. J. Anaesth. 107, 774-781. https://doi.org/10.1093/bja/aer291

575 Zhang, L., Meng, J., Ban, Y., Jalodia, R., Chupikova, I., Fernandez, I., Brito, N., Sharma, U., Abreu, M.T.,

576 Ramakrishnan, S., Roy, S., 2019. Morphine tolerance is attenuated in germfree mice and reversed

577 by probiotics, implicating the role of gut microbiome. Proc. Natl. Acad. Sci. 116, 13523-13532.

$578 \quad$ https://doi.org/10.1073/pnas.1901182116 


\section{Figure legends:}

Figure 1. $\beta$-arrestin-2 knockout abolishes tolerance to overnight morphine exposure in DRG neurons.

581 Representative short-pulse (10 ms) whole-cell current-clamp traces of naïve and overnight morphine-

582 treated (A) Barr2 WT or (B) ßarr2 KO DRG neurons. Action potential is generated at baseline (black) and

583 after 16 minutes of acute $3 \mu \mathrm{M}$ morphine challenge (red). Threshold potential, which is a measure of

584 neuronal excitability, is extrapolated from the point on the action potential derivative trace, where the

585 action potential differential $(\mathrm{dV} / \mathrm{dt})>0$. (C) Threshold potentials of $\beta$ arr2 WT and $\beta$ arr2 KO DRG neurons

586 at baseline and after bath exposure to $3 \mu \mathrm{M}$ morphine for up to 16 minutes. Data analyzed by 3-way

587 repeated-measures ANOVA with Bonferroni's post-test. Significant effect of genotype $x$ overnight

588 morphine treatment $x$ acute morphine challenge on threshold potential $[F(1,22)=5.73 ; P=0.03]$ was

589 detected. ${ }^{* * *} \mathrm{P}<0.001$ vs. baseline and ' $\mathrm{s}$ ' is not significant $(\mathrm{P}>0.05)$. Scatter represents individual cells

590 (D) Threshold potential change from baseline following acute $3 \mu \mathrm{M}$ morphine challenge for up to 16

591 minutes. Data analyzed by 2-way ANOVA with Bonferroni's post-test. Significant main effect of genotype

$592 \times$ overnight morphine treatment on threshold potential $[F(1,24)=7.14 ; P=0.01]$ was detected. Data

593 are mean \pm S.E.M. Scatter represents individual cells. ${ }^{*} P<0.01$ and ' $n s$ ' is not significant $(P>0.05)$. Naïve

594 Barr2 WT: $N=4$ mice $n=7$ cells; Overnight-treated $\beta$ arr2 WT: $N=3, n=5$; Naïve $\beta$ arr2 KO: $N=5, n=7$;

595 and Overnight-treated $\beta$ arr2 KO: $\mathrm{N}=3, \mathrm{n}=7$.

597 Figure 2. Overnight exposure to TRV130 does not produce tolerance in $\beta$-arrestin-2 WT DRG neurons.

598 Representative long-pulse (100 ms) current-clamp traces of (A) naïve and (B) overnight TRV130-treated

599 Barr2 WT DRG neurons. Action potential is generated at baseline (black) and after acute 50 nM TRV130

600 challenge (red). Threshold potential is extrapolated from the point on the action potential derivative

601 trace, where the action potential differential $(\mathrm{dV} / \mathrm{dt})>0$. (C) Threshold potentials of naïve and overnight 
200 nM TRV130-treated DRG neurons isolated from male $\beta$ arr2 WT mice at baseline and after acute

603 challenge with $50 \mathrm{nM}$ TRV130. 2-way repeated-measures ANOVA did not detect a main effect of

604 overnight treatment $x$ acute TRV130 challenge on threshold potential $[F(1,16)=0.27 ; P=0.61]$;

605 however, a significant effect of acute TRV130 challenge $[F(1,16)=16.56 ; P<0.001]$ on threshold

606 potential was observed. Data, therefore, analyzed by multiple 2-tailed paired t-tests with two-stage

607 step-up method of Benjamini, Krieger and Yekutieli. The False Discovery Rate was set to 5\%. *Adjusted

$608 \mathrm{P}<0.05$ and **adjusted $\mathrm{P}<0.01$ vs. baseline. (D) Threshold potential change from baseline after acute 50

609 nM TRV130 challenge. ' $n s^{\prime}$ is not significant $(P>0.05)$ by 2-tailed unpaired t-test. Naïve: $N=5, n=9$; and

610 Overnight-treated: $\mathrm{N}=2, \mathrm{n}=9$. Data are mean \pm S.E.M. Scatter represents individual cells.

Figure 3. Acute antinociceptive tolerance in mice is mediated by $\beta$-arrestin-2. (A) Warm-water tail-

614 withdrawal antinociception in $\beta$-arrestin-2 WT or KO mice pre-treated with either saline or $100 \mathrm{mg} / \mathrm{kg}$

615 morphine s.c. on Day 1 and acutely challenged with $10 \mathrm{mg} / \mathrm{kg}$ morphine s.c on Day 2. Data are \%MPE \pm

616 S.E.M represent Day 2 results. Scatter represents individual mice. $\beta$-arrestin-2 WT mice: $\mathrm{N}=10 /$ group;

$617 \beta$-arrestin-2 KO mice: N = 9/group. Data analyzed by 2-way ANOVA with Bonferroni's post-test. Main

618 effect of Day 1 pre-treatment $x$ genotype on \%MPE was significant $[F(1,34)=5.139 ; P=0.03]$.

$619 * * * P<0.01$ and ' $n s^{\prime}$ is not significant $(P>0.05)$. (B) Warm-water tail-withdrawal antinociception in $\beta$ -

620 arrestin-2 WT mice pre-treated with either saline or $30 \mathrm{mg} / \mathrm{kg}$ TRV130 s.c. on Day 1 and acutely

621 challenged with $3 \mathrm{mg} / \mathrm{kg}$ TRV130 s.c on Day 2. Data are \%MPE \pm S.E.M and represent Day 2 results.

622 Scatter are individual mice. $\beta$-arrestin-2 WT mice: $N=5$ /group. Data analyzed by 2-tailed unpaired t-test.

623 ' $\mathrm{ns}$ ' is not significant $(\mathrm{P}>0.05)$. WT mice injected with $100 \mathrm{mg} / \mathrm{kg}$ morphine on Day 1 respond

624 significantly less to acute morphine challenge on Day 2 vs. saline controls, indicating tolerance. Mice

625 devoid of $\beta$-arrestin- 2 or pre-treated with TRV130 on Day 1 continue to respond to the acute morphine 
or TRV130 challenge on Day 2, respectively, indicating no acute antinociceptive tolerance development

627 in absence of $\beta$-arrestin-2 activation.

629 Figure 4. $\beta$-arrestin-2 knockout does not prevent tolerance in DRG neurons isolated from chronic

630 morphine-treated mice. Representative current-clamp traces of DRG neurons isolated from (A) $\beta$ arr2

631 WT or (B) Barr2 KO male mice treated with $50 \mathrm{mg}$ morphine pellet (MP) for 7 days. Action potential is

632 generated at baseline (black) and after 16 minutes of acute $3 \mu \mathrm{M}$ morphine challenge (red). Threshold

633 potential is extrapolated from the point on the action potential derivative trace, where the action

634 potential differential $(\mathrm{dV} / \mathrm{dt})>0$. (C) Threshold potential values of individual neurons from MP $\beta$ arr2 WT

635 or MP $\beta$ arr2 KO mice at baseline and after $3 \mu \mathrm{M}$ morphine challenge for up to 16 minutes. Main effect of

636 genotype $x$ acute morphine challenge on threshold potential was not observed $[F(1,15)=1.57 ; P=0.23]$

637 by 2-way repeated-measures ANOVA. The test also did not detect an effect of acute morphine challenge

638 on threshold potential $[F(1,15)=1.20 ; P=0.29]$. (D) Threshold potential change from baseline after

639 acute $3 \mu \mathrm{M}$ morphine challenge. ' $n s^{\prime}$ is not significant $(P>0.05)$ by 2-tailed unpaired t-test. $\beta a r r 2 ~ W T: ~ N=$

6404 mice, $n=7$ cells; and $\beta$ arr2 KO: $N=5, n=10$. Data are mean \pm S.E.M. Scatter represents individual

641 cells.

642

Figure 5. Long-term morphine tolerance develops to tail-withdrawal antinociception in male mice in

644 the absence of $\beta$-arrestin-2. Long-term morphine tolerance was evaluated by acutely challenging male

645 Barr2 WT (left) or KO (right) mice implanted with placebo or $50 \mathrm{mg}$ morphine pellet with $10 \mathrm{mg} / \mathrm{kg}$

646 morphine s.c. on days (A) 1, (B) 3, (C) 4 or (D) 7, and tail-withdrawal latencies before and after challenge

647 were compared. Data are mean \pm S.E.M. Scatter represents individual animals. ${ }^{* *} \mathrm{P}<0.01,{ }^{* * *} \mathrm{P}<0.001$

648 and ' $n s$ ' (not significant, $\mathrm{P}>0.05$ ) vs. baseline by 2-way repeated-measures ANOVA with Bonferroni's

649 post-test. Day 1: N=5/group; Day 3: N = 7 (PP WT), 5 (PP KO), 7 (MP WT) and 6 (MP KO); Day 4: N = 7 (PP 
WT), 5 (PP KO), 7 (MP WT) and 7 (MP KO); Day 7: N = 6 (PP WT), 8 (PP KO), 7 (MP WT) and 7 (MP KO).

Both, $\beta$ arr2 WT and KO mice develop antinociceptive tolerance over 7 days of morphine exposure,

652 indicating that long-term antinociceptive tolerance in male mice is independent of $\beta$-arrestin-2.

Figure 6. Long-term morphine tolerance develops to tail-withdrawal antinociception in female mice in

(left) or KO (right) mice implanted with placebo or $25 \mathrm{mg}$ morphine pellet with $10 \mathrm{mg} / \mathrm{kg}$ morphine s.c.

on days (A) $1,(B) 3,(C) 4$ or (D) 7, and tail-withdrawal latencies before and after challenge were

compared. Data are mean \pm S.E.M. Scatter represents individual animals. ${ }^{* * *} P<0.001, \# P=0.06$ and 'ns'

659 (not significant, $\mathrm{P}>0.05$ ) vs. baseline by 2-way repeated-measures ANOVA with Bonferroni's post-test.

660 Day 1: $N=4$ (PP WT) and rest 5/group; Day 3: N = 5 (PP WT), 5 (PP KO), 11 (MP WT) and 6 (MP KO); Day

4: $\mathrm{N}=5$ (PP WT), 6 (PP KO), 10 (MP WT) and 4 (MP KO); Day 7: N = 5 (PP WT), 5 (PP KO), 7 (MP WT) and antinociceptive tolerance in female mice is independent of $\beta$-arrestin-2.

665 Figure 7. Cumulative morphine dose response curve of male and female $\beta$-arrestin-2 kO mice.

666 Cumulative morphine dose response curves of 7-day placebo-pelleted (PP) and morphine-pelleted (MP)

667 male and female mice were compared to evaluate the effect of $\beta$-arrestin-2 deletion on warm-water

668 tail-withdrawal antinociception. Each point is \%MPE \pm S.E.M. Males: $N=6 /$ group. Females: 7/group.

669 ED50 of $50 \mathrm{mg} \mathrm{MP}$ male mice is significantly right-shifted compared to PP male mice [MP: 63.9 (42.4-

670 113.7) vs. PP: 2.90 (1.89-4.33)]. Similarly, ED50 of $25 \mathrm{mg}$ MP female mice is significantly right-shifted

671 compared to PP female mice [MP: 41.82 (31.66-55.61) vs. PP: 1.56 (1.25-1.98)]. Thus, antinociceptive

672 tolerance develops in both male and female mice despite the absence of $\beta$-arrestin- 2 
bioRxiv preprint doi: https://doi.org/10.1101/2020.11 5.383620.thistersionostopember 15, 2020. The copyright holder for this preprint

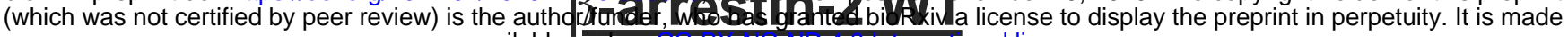
available under aCC-BY-NC-ND 4.0 international license.

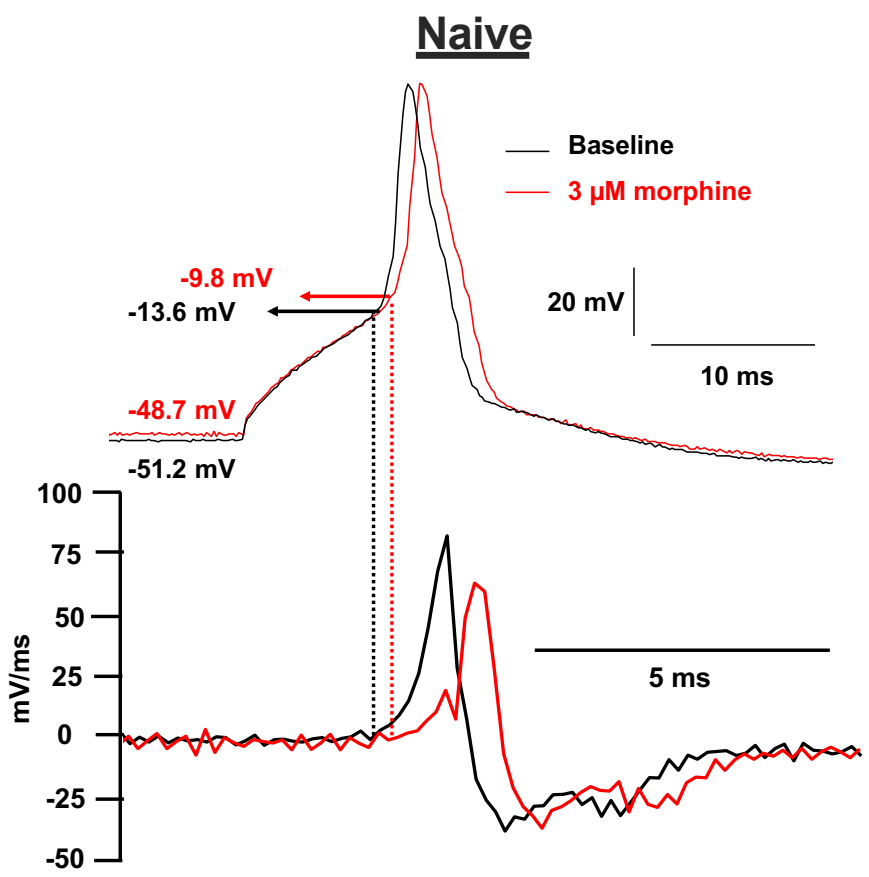

\section{$+10 u M$ morphine overnight}

\section{$\beta$-arrestin-2 KO}

Naive
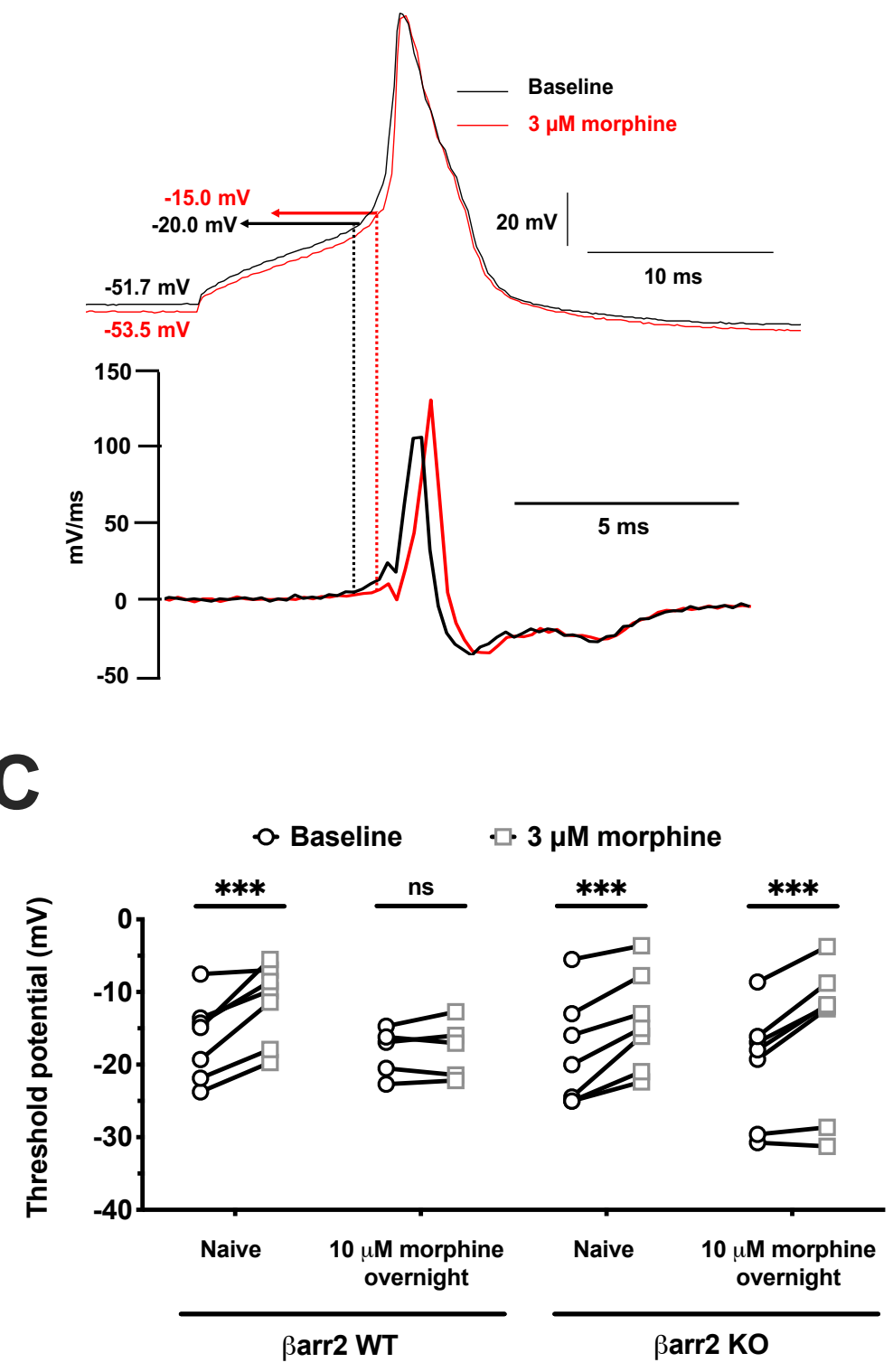

\section{$+10 u M$ morphine overnight}

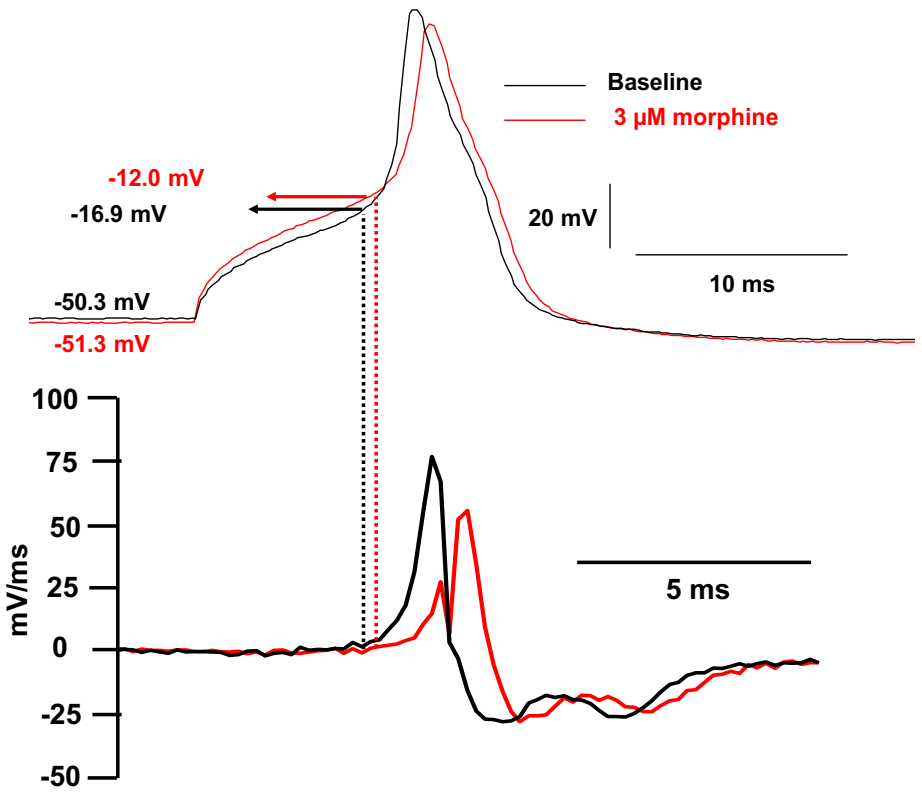

D

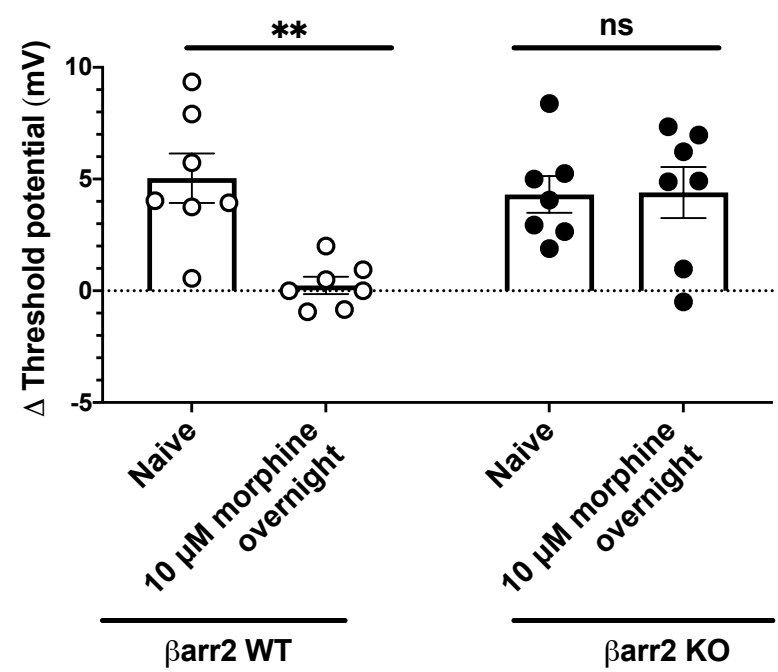


Naive $\beta$-arrestin-2 WT

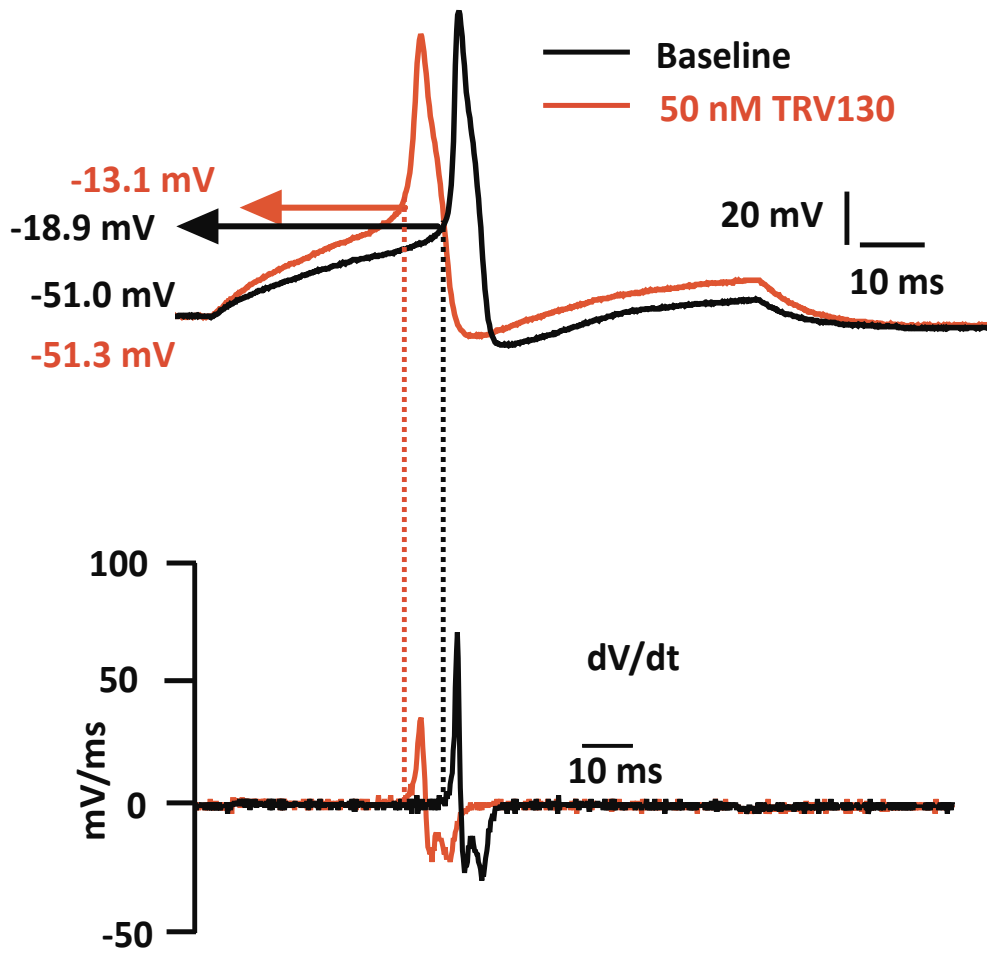

C

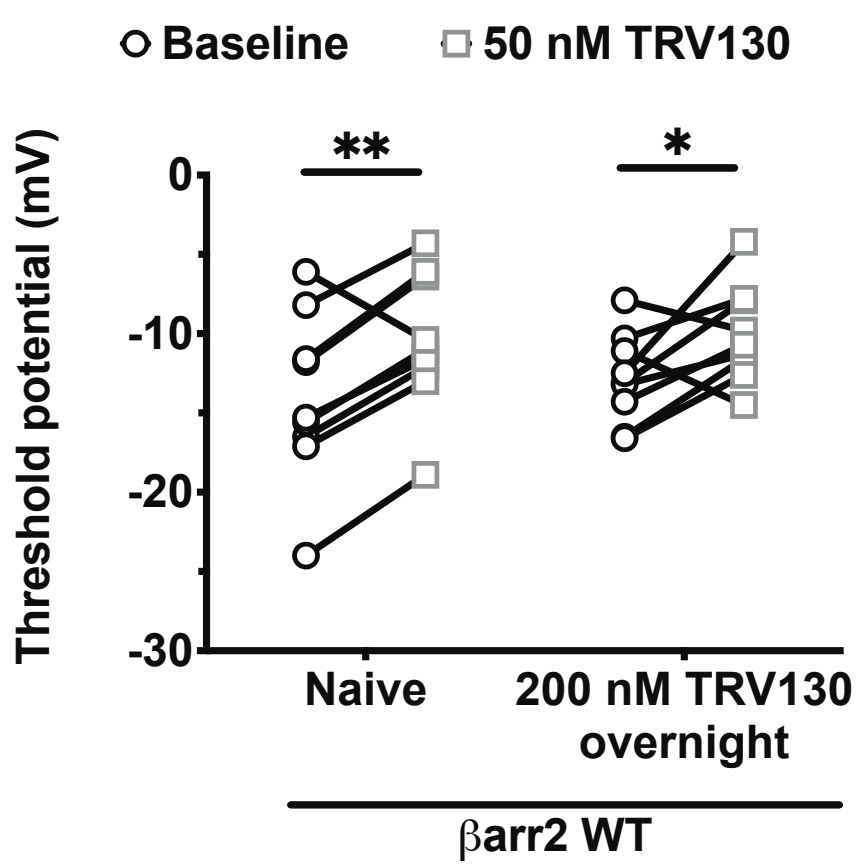

+200 nM TRV130 overnight

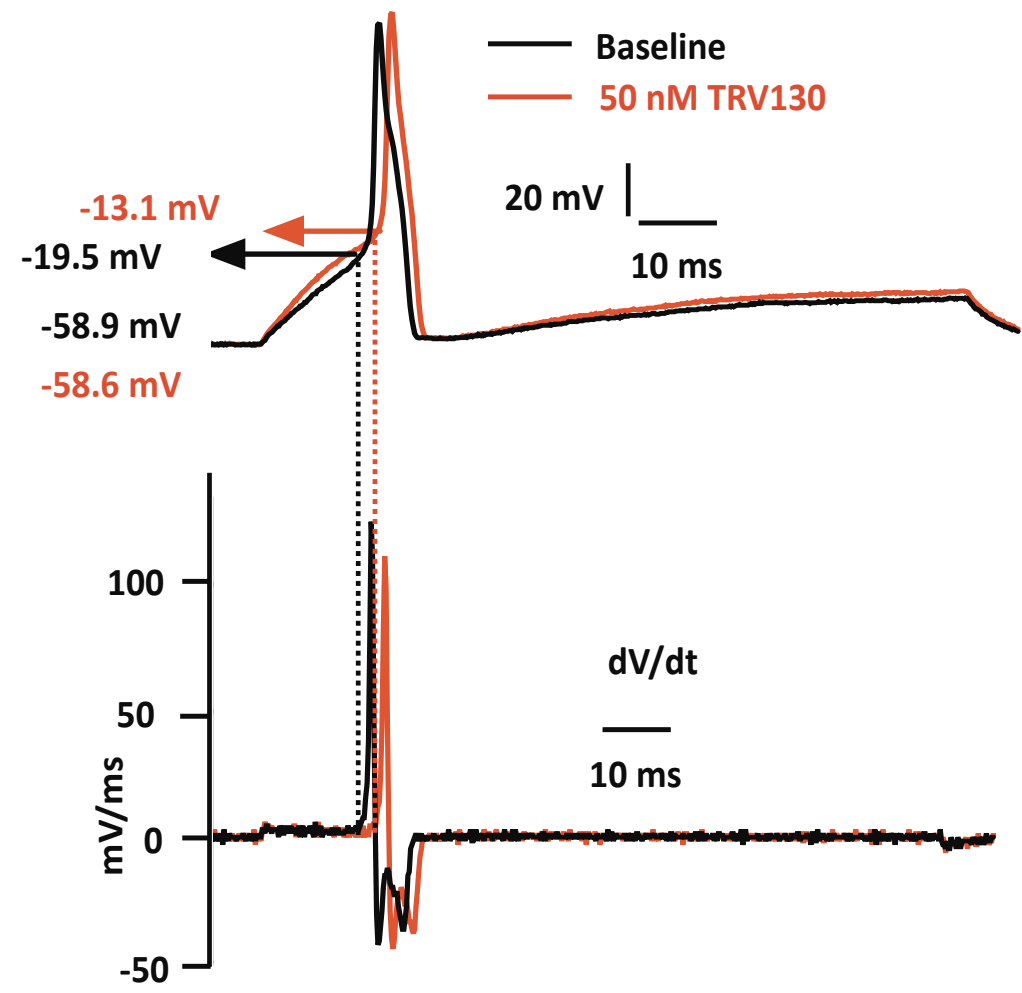

D

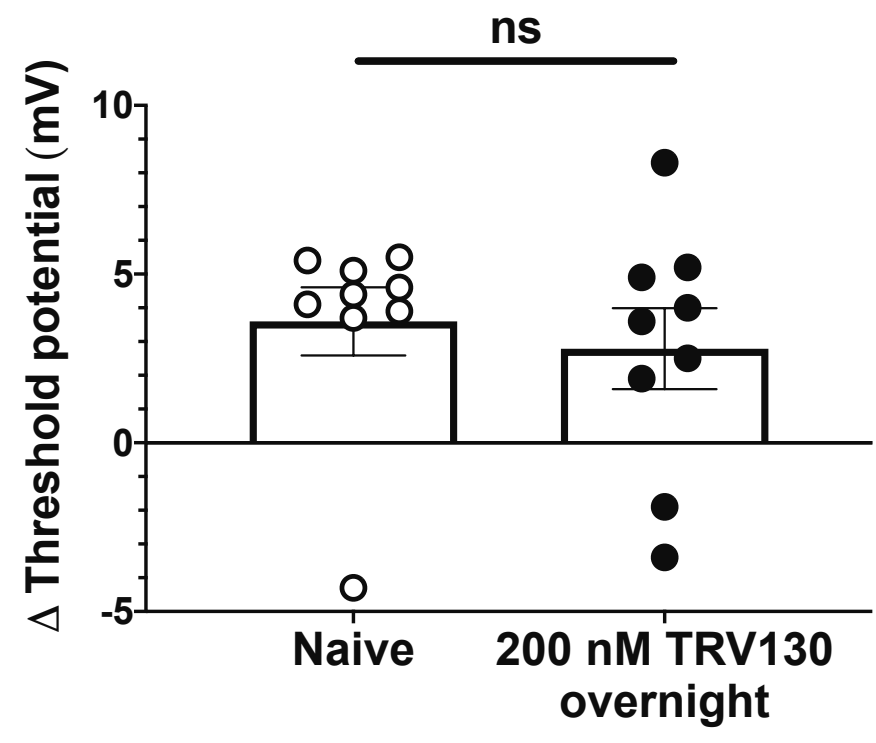

ßarr2 WT 

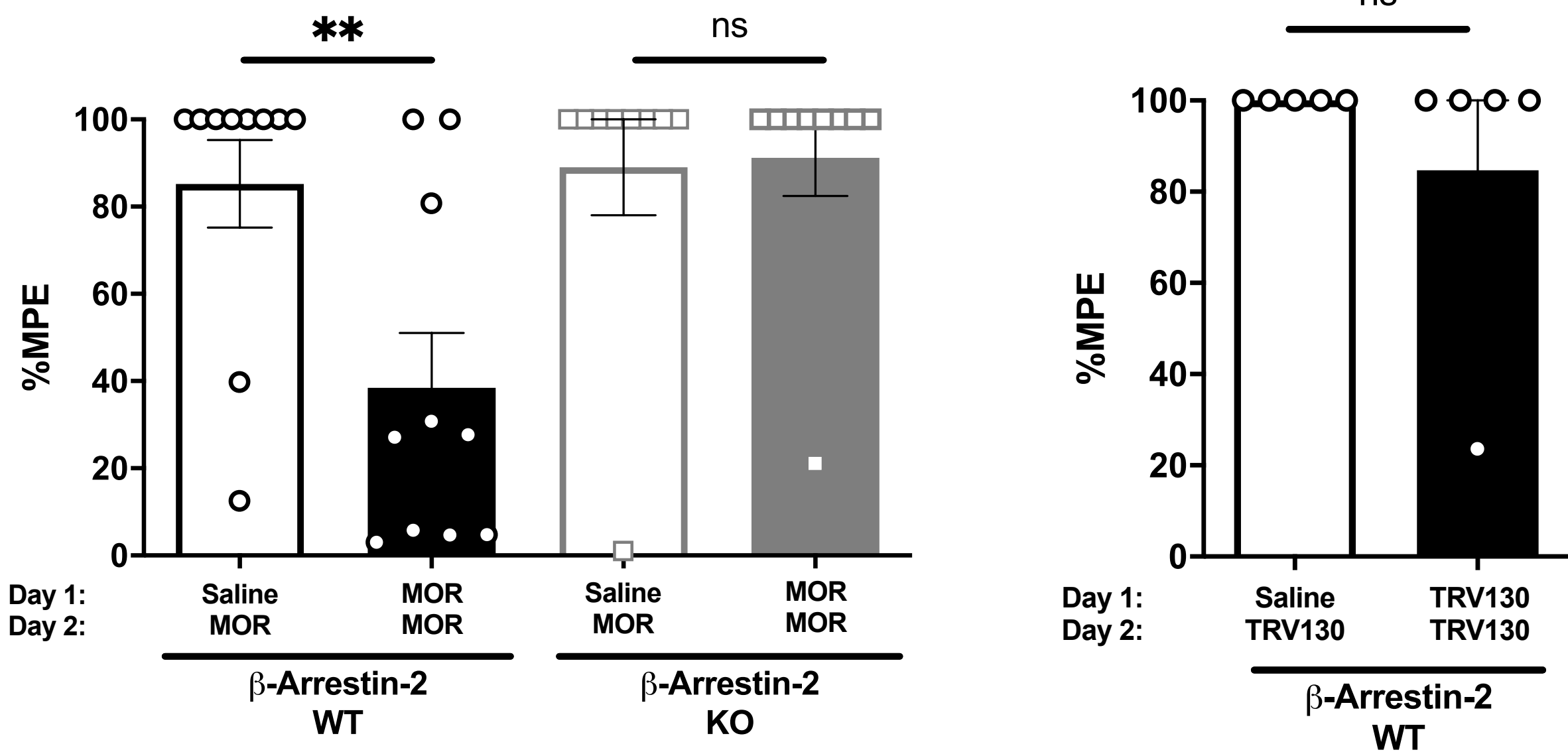

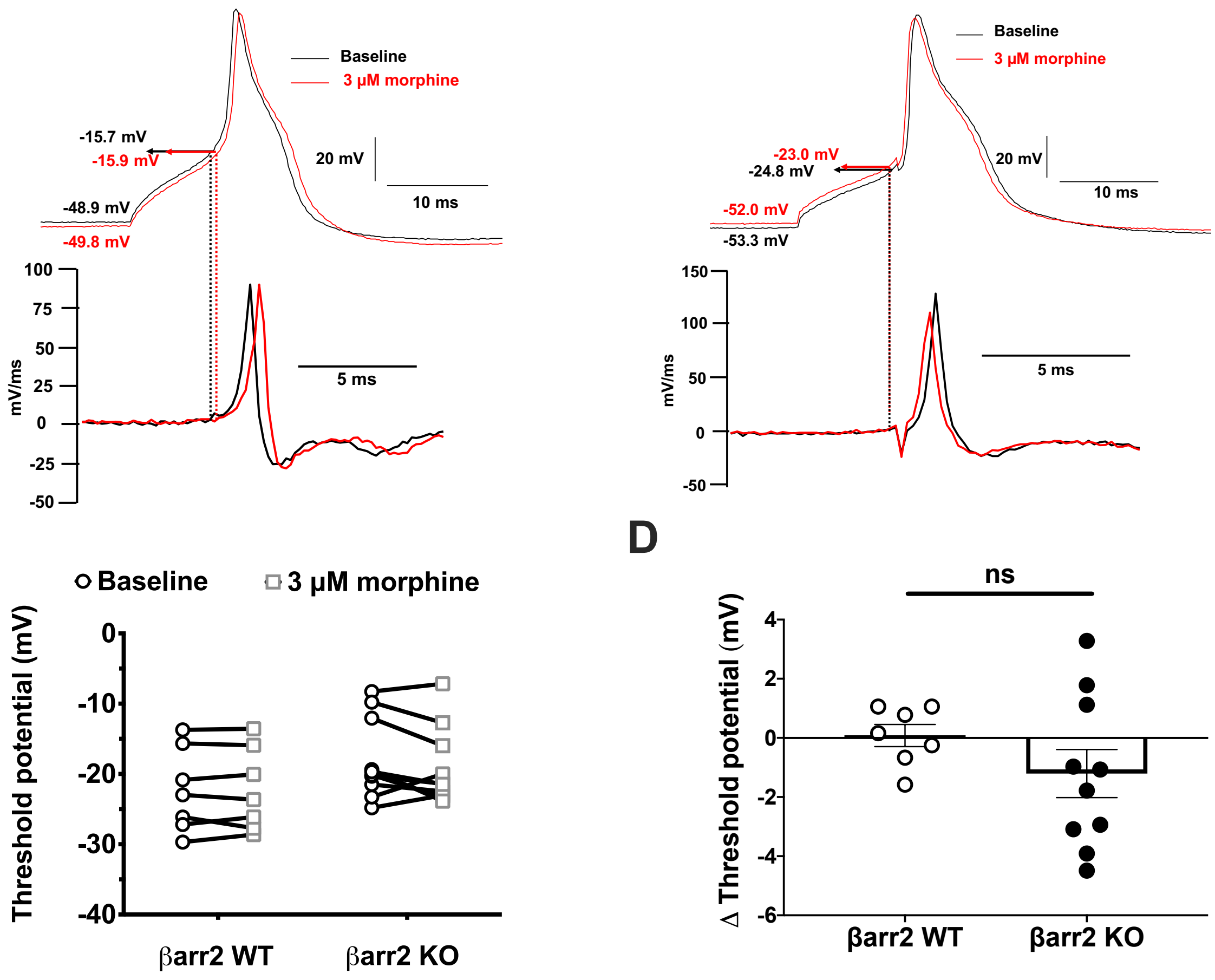

D

$50 \mathrm{mg}$ morphine pellet for 7 days

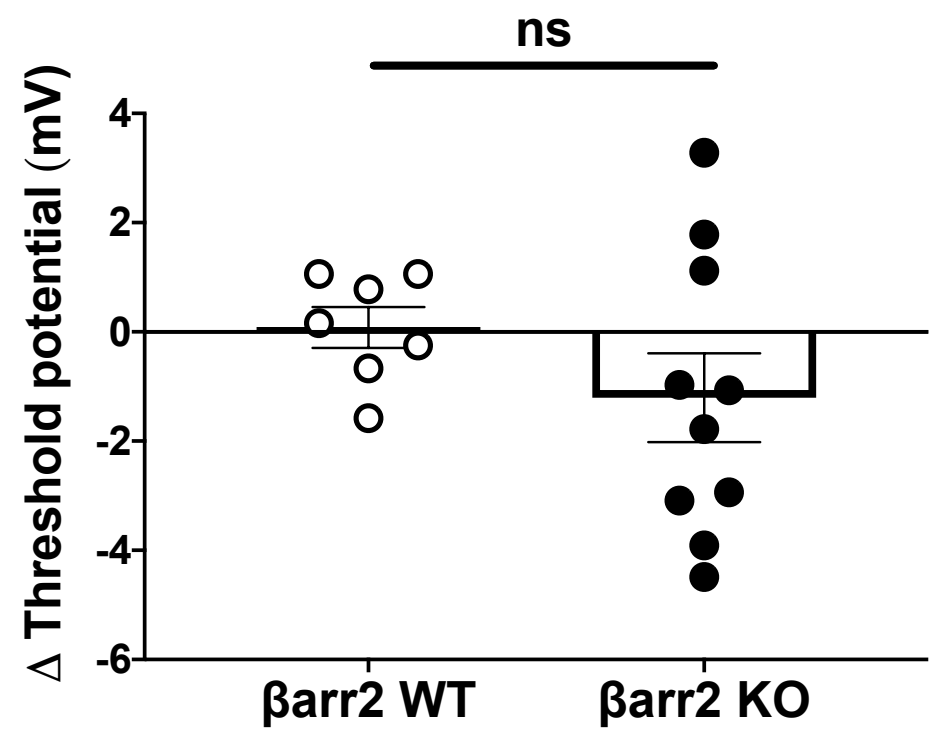

$50 \mathrm{mg}$ morphine pellet for 7 days 


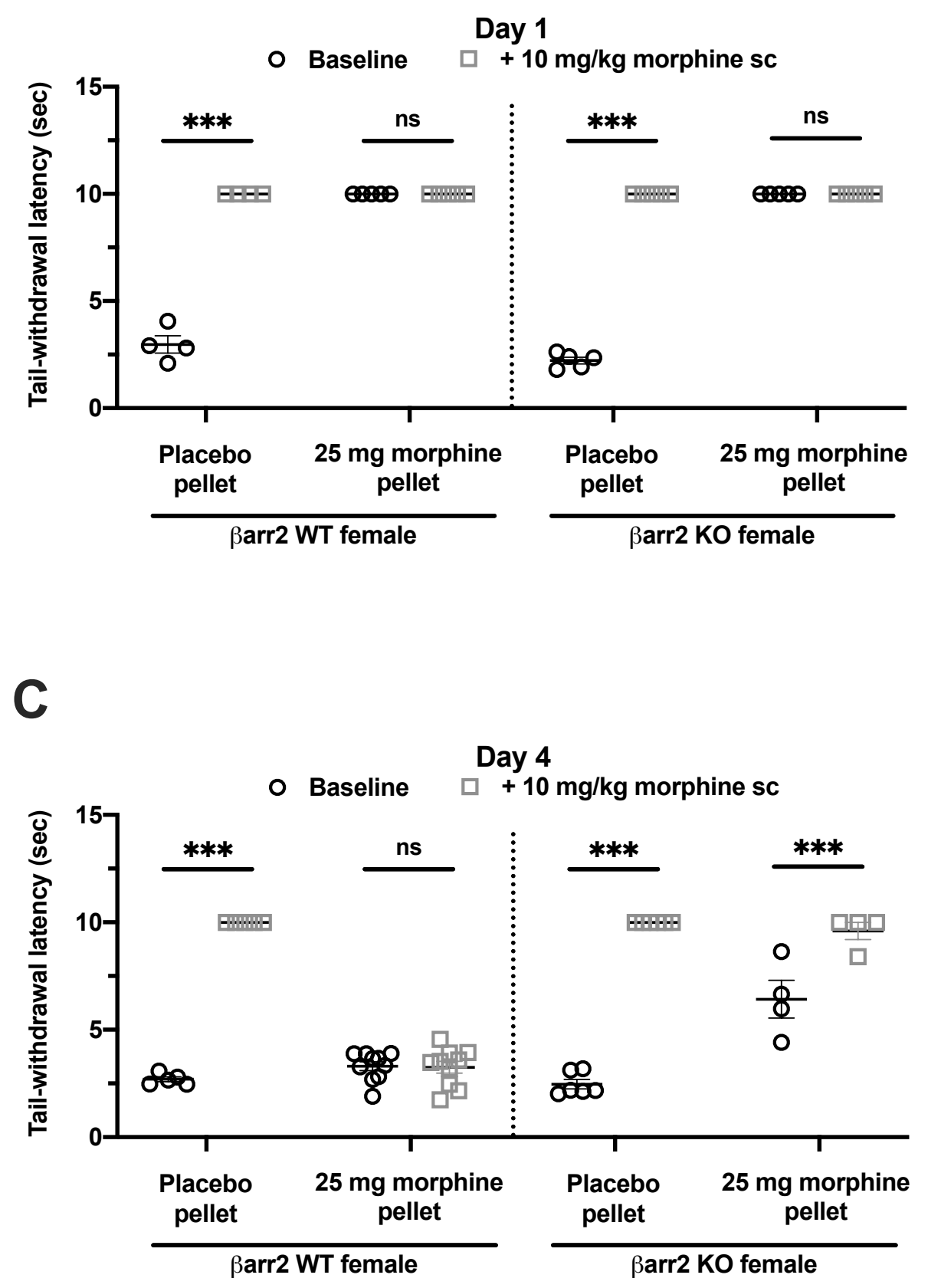

Day 3

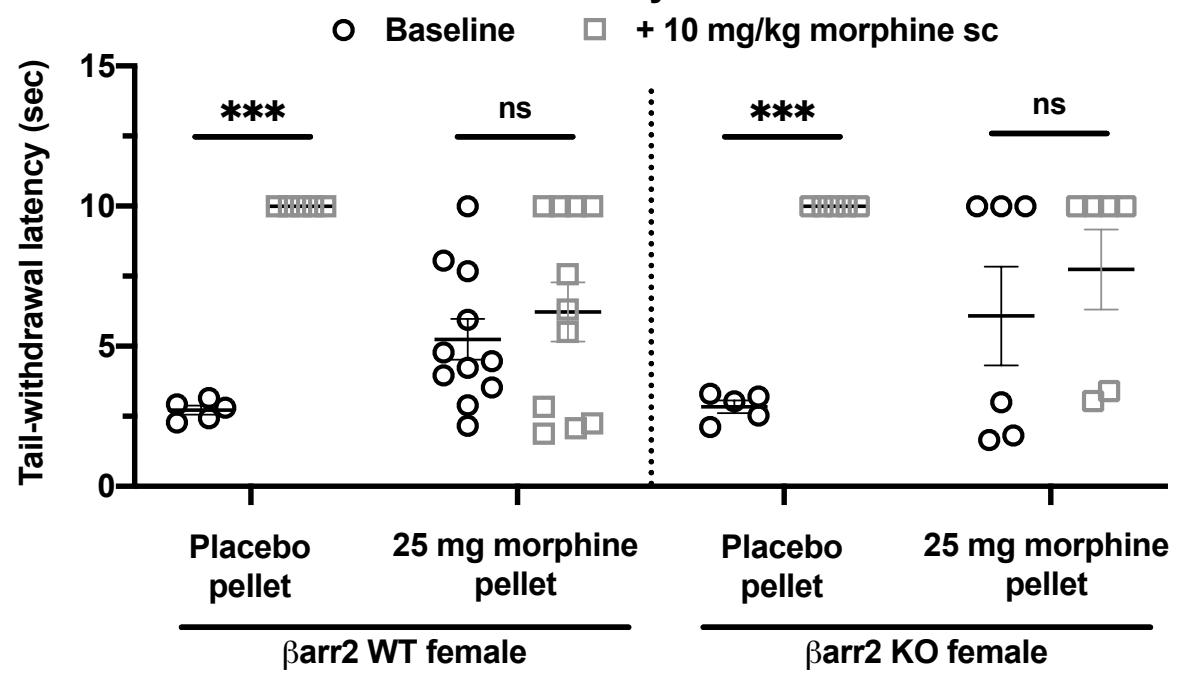

D

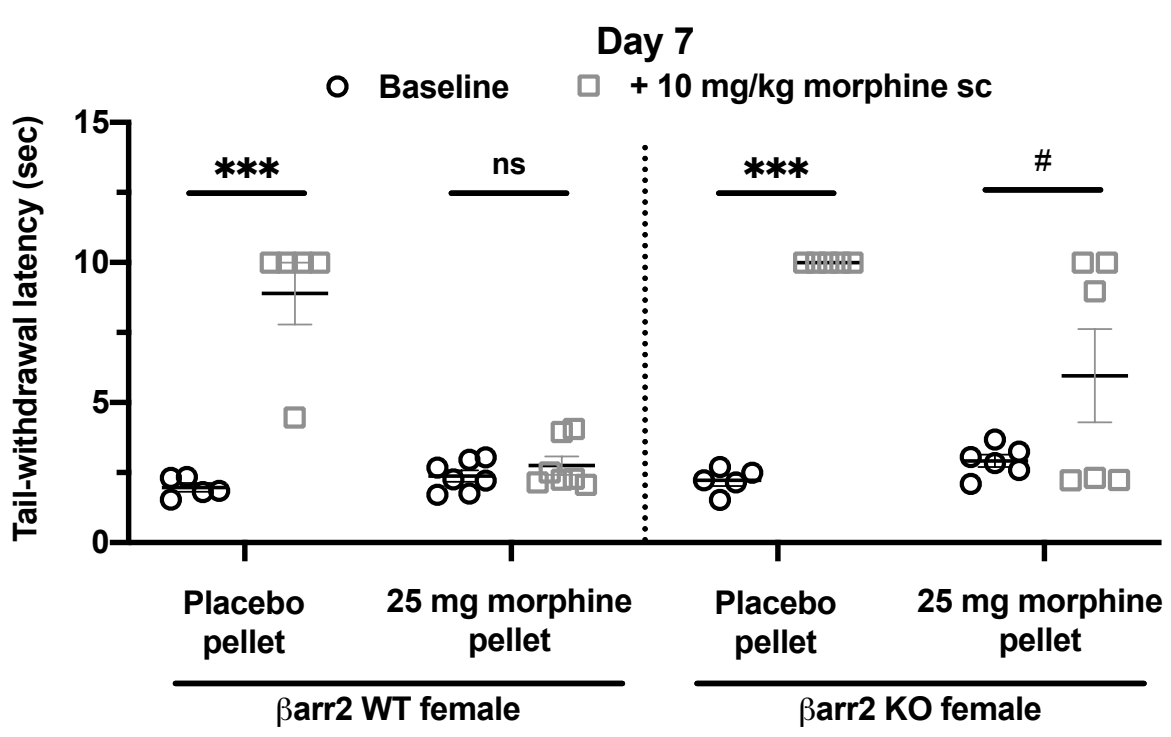




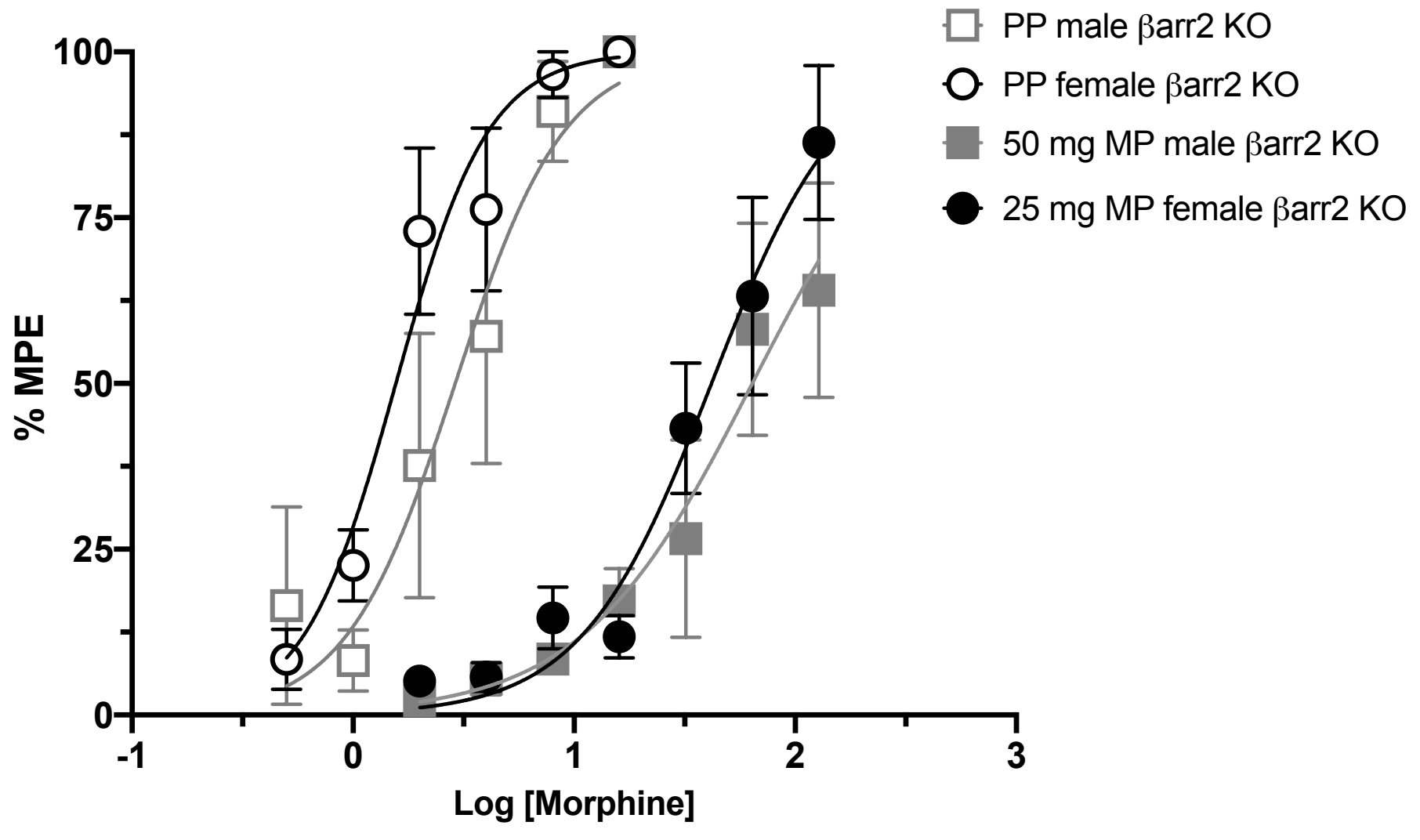

